\title{
Dynamic mechanical analysis of Scots pine and three tropical hardwoods
}

Ashaduzzaman, Md; Hale, Mike; Ormondroyd, Graham; Spear, Morwenna

\section{International Wood Products Journal}

DOI:

$10.1080 / 20426445.2020 .1799910$

Published: 01/10/2020

Peer reviewed version

Cyswllt i'r cyhoeddiad / Link to publication

Dyfyniad o'r fersiwn a gyhoeddwyd / Citation for published version (APA):

Ashaduzzaman, M., Hale, M., Ormondroyd, G., \& Spear, M. (2020). Dynamic mechanical analysis of Scots pine and three tropical hardwoods. International Wood Products Journal, 11(4), 189-203. https://doi.org/10.1080/20426445.2020.1799910

\footnotetext{
Hawliau Cyffredinol / General rights

Copyright and moral rights for the publications made accessible in the public portal are retained by the authors and/or other copyright owners and it is a condition of accessing publications that users recognise and abide by the legal requirements associated with these rights.

- Users may download and print one copy of any publication from the public portal for the purpose of private study or research.

- You may not further distribute the material or use it for any profit-making activity or commercial gain

- You may freely distribute the URL identifying the publication in the public portal ?
}

Take down policy

If you believe that this document breaches copyright please contact us providing details, and we will remove access to the work immediately and investigate your claim. 


\title{
Dynamic mechanical analysis of Scots pine and three tropical hardwoods
}

\author{
Md Ashaduzzaman ${ }^{1}$, Michael Hale ${ }^{2}$, Graham Ormondroyd ${ }^{2}$, Morwenna Spear ${ }^{2 *}$ \\ 1 Forestry and Wood Technology Discipline, Khulna University, Khulna-9208, \\ Bangladesh \\ 2 The BioComposites Centre, Bangor University, Deiniol Road, Bangor, LL57 2UW, \\ UK \\ * corresponding author m.j.spear@bangor.ac.uk
}

\section{Abstract}

Dynamic mechanical analysis (DMA) was used to investigate the viscoelastic behaviour of four species of wood, Scots pine, Gmelina, Obeche and Alstonia. Three frequencies $(0.1,1.0$ and $10 \mathrm{~Hz})$ were used over a temperature range of -150 to $+150^{\circ} \mathrm{C}$. All the wood species showed $\tan \delta$ peaks corresponding with secondary relaxations in the expected range. The low temperature ( $\gamma$ peak) was seen at -115 to $83^{\circ} \mathrm{C}$, differing between species and with frequency. $\beta$ peaks relating to hemicellulose relaxations in association with water molecules were observed, at two locations for Scots pine and three locations in hardwoods. The $\alpha$ peak for lignin lay outside the temperature range studied. Differences in $\beta$ peaks are proposed to relate to the composition of hemicellulose, and be influenced by structure and level of heterogeneity in the amorphous polymer domains; differing between the wood species studied, which is in-line with currently proposed cell wall polymer models.

Keywords: Dynamic mechanical analysis (DMA), secondary relaxation, Scots pine, Gmelina, Obeche, Alstonia

\section{$\underline{\text { Introduction }}$}

Dynamic mechanical analysis is a widely recognised technique for investigating the viscoelastic properties of polymers and composite materials. It can be used to determine the glass transition temperature $\left(\mathrm{T}_{\mathrm{g}}\right)$ of polymers and observe relaxation phenomena in plasticised systems (Havimo 2009, Menard and Menard 2015). This is achieved by measuring the storage modulus (E') and loss modulus (E') for the material under test, and evaluating changes in magnitude of $\tan \delta$ (which is the ratio of loss modulus to storage modulus). As the loss angle $\delta$ is the phase angle between the applied stress and the observed strain during sinusoidal deformation in time, the tangent of this angle provides a measure of the damping, or internal friction within the material (if loaded within the linear range). Peaks in $\tan \delta$ coincide with large decreases in storage modulus related to glass transition temperature $T_{g}$ and with secondary relaxation events in the polymer (Menard and Menard 2015). The magnitude of secondary peaks is typically smaller than $T_{g}$ peaks.

As wood is a material principally composed of three organic polymeric materials (cellulose, hemicellulose and lignin), DMA can also be used to investigate viscoelastic phenomena in this complex material, or its component parts (Salmén 1984, Wert et al. 1984, Kelley et al. 1987, Sharma et al. 2015, Startsev et al. 2017). Many studies have been undertaken in the fully saturated condition, to assist elucidation of softening processes in chemical or thermomechanical pulping (Salmén 
1984, Olsson and Salmén 1992, Placet et al. 2007), other solvents such as ethylene glycol may also be used (Fabiyi et al. 2011) to extend the temperature range observed. However, data from these studies differs significantly from studies undertaken at moderate relative humidities and ambient conditions. Furthermore, work with DMA of wood under changing relative humidity has been investigated more recently (Ebrahimzadeh and Kubat 1993, Zhan et al. 2015, Li et al. 2018) and reveals additional influences on damping and stress relaxation, resulting directly from moisture uptake and loss, and from transient effects of moisture movement within the wood. There is a growing recognition that experimental conditions must be fully reported and considered when comparing the results of DMA studies.

Different species of wood are known to have widely varying proportions of the cell wall polymers, and most notably there are differences in the composition of hemicelluloses and of lignin between softwoods and hardwoods (Pettersen 1984). As DMA quantifies responses in the amorphous component of polymers, the different quantities of hemicellulose and lignin polymers are likely to show differences in DMA relating to this composition change, either in peak intensity, or in peak location. In addition, the different composition of lignin (ratio of syringyl and guaiacyl monomers) has been studied (in the saturated state, ethylene glycol) by Horvath et al. (2011). By contrast, the hemicellulose composition has to our knowledge been frequently ignored due to the dominance of lignin related peaks in studies on saturated samples. However, the hygroscopicity of hemicellulose, and the plasticisation effect that is associated with adsorbed moisture in the wood cell wall mean that hemicellulose must also be considered in DMA analyses.

In addition, wood is an anisotropic material, with three principle orientations relating to the grain laid down during tree growth. It is increasingly reported that there are differences in behaviour between test orientations, even between tangential and radial (Backman and Lindberg 2001). These differences are likely to relate to cell wall composition and ultrastructure. It is important to note that the wide range of potential orientations of the wood grain relative to the test sample geometry may influence observed results. For example tan $\delta$ events in longitudinal specimens are reported to occur at higher temperatures than in radial or tangential specimens (Hoffman et al. 1990, results of dielectric analysis). Differences in peak intensity and temperature have also been observed for radially and tangentially aligned test samples, with the greater intensity of tangential samples indicating that the mode of test is acting on a greater proportion of material (Backman and Lindberg 2001).

Wood is a hygroscopic material, and displays strong interactions with moisture, which has a strong influence on the static strength properties of wood (Gerhards 1982), and the time dependent properties of wood, such as creep (Holzer et al. 1989). Therefore moisture content also has a strong effect on the viscoelastic properties of wood, including the location of relaxations seen in DMA (Kelley et al. 1987, Backman and Lindberg 2001, Startsev et al. 2017). In particular, the relaxation phenomena vary to a great extent between various reported types of 'oven dry' wood, depending on the use of low or high temperatures with or without vacuum to partially or completely remove moisture from adsorbed sites within the cell wall (Obataya et al. 2001). It has been proposed that the presence of moisture acts as a plasticiser for the wood in a manner similar to the action of plasticizer in pure polymer systems (Becker and Noack 1968, Entwistle 2005). 
When DMA is applied to wood, the complex interaction between these factors, namely the polymer components present, their distribution within the cell wall, the alterations between cell wall structure in the principle orientations (microstructure), and the influence of moisture content and relative humidity of the test conditions, frequently leads to ambiguity in interpretation of the phenomena. While many researchers have been rigorous in their approach to using DMA on wood samples, others have neglected to report key details about sample moisture content at time of test; sample orientation (growth rings relative to sample geometry and test axis); and test set up parameters (span length, sample cross section, frequency or other factors). This has maintained an unnecessary level of uncertainty in comparing between research groups or between timber species, test modes, and experimental hypothesis.

This study has considered the viscoelastic properties of four species of wood in three point bending mode, with the long axis of the test specimen parallel to the longitudinal direction of the wood. An attempt has been made to introduce consistency and comparability to the study of wood species differences with DMA by utilising standardised conditioning procedures and sample orientations. The selected species were chosen for their likely permeability and moderate density, as candidate species for a resin treatment modification to enhance durability (Ashadduzaman et al. 2013). However, this range of species allowed the consideration of a variety of wood anatomies in the context of DMA analysis. The selected softwood was Scots pine and this was compared with three tropical hardwoods Gmelina, Obeche and Alstonia.

\section{$\underline{\text { Nomenclature }}$}

It is known that the majority of DMA studies on wood report three main $\tan \delta$ events, depending on the range of temperatures used. Typically peaks are named from high to low temperature as the $\alpha, \beta$ and $\gamma$ peaks, a convention which will also be applied in this paper. Under this method the $\alpha$-peak often equates to $\mathrm{T}_{\mathrm{g}}$ of the polymer under investigation, while $\beta$ - and $\gamma$-peaks are secondary loss peaks (Menard and Menard 2015, Heijboer 1977). However, when working with wood the presence of several amorphous polymers requires caution in applying this assumption. In addition, there are differences in choice of nomenclature between authors, with some using $\alpha_{1}, \alpha_{2}$ and $\beta$ (Kelley et al. 1987), and others $\alpha, \beta$, and $\gamma$ (Backman and Lindberg 2001). In some studies where the temperature range is low (e.g. -120 to $40^{\circ} \mathrm{C}$, Jiang and $\mathrm{Lu} 2008$, $\mathrm{Li}$ et al. 2018) the assignment from high to low leads to very different peaks being labelled as $\alpha$ and $\beta$ than in studies which use a wider range. As studies on wood are often conducted over different temperature ranges this may lead to differences in which $\tan \delta$ peak is observed as the highest within the measured range and consequently identified as $\alpha$, whereas in single polymer studies $T_{\alpha}$ would typically be the $T_{g}$, with $T_{\beta}$ and $T_{\gamma}$ being secondary peaks (Menard and Menard 2015). As wood is a multi-component system this ambiguity of nomenclature between studies and researchers is understandable.

A study by Sugiyama et al. (1998) attributed the three main peaks in wood DMA temperature scans to the events shown in Table 1. Additional notes, especially observed ranges relating to observations from other studies are also provided. It is clear though that the $\alpha$ peak occurs at high temperatures, and is likely to occur just 
outside the range of study in this experiment. Therefore, within this paper peaks will be labelled as $\beta_{1}, \beta_{2}$ and $\gamma$ to reflect the different components of the moisture-related hemicellulose relaxation. These largely map to the $\alpha_{1}, \alpha_{2}$ and $\beta$ peaks of Kelley's study (1987), while synching with reported peaks in other works studying the larger range.

\section{Table 1 here}

The large range of temperatures over which the $\alpha$ and $\beta$ relaxations may occur (Table 1 ), and the role of moisture in this shift, has made interpretation and comparison of results between laboratories challenging. The revised nomenclature is a proposal to address this. However it is clear that increasing moisture content tends to shift both the $\alpha$ and $\beta$ peaks to lower temperatures. In high moisture content wood the $\gamma$ peak may be obscured by overlapping with the $\beta$ peak (Obataya et al. 2001). As the $\beta$ peak relates primarily to the moisture within hemicellulose regions of the wood, it is sometimes referred to as a hemicellulose event. This is not to be considered to be a $T_{g}$ of hemicellulose however, it is a relaxation or molecular motion. Dry hemicellulose is reported to have $\mathrm{T}_{\mathrm{g}}$ at $150-220^{\circ} \mathrm{C}$ (Back and Salmén, 1982) and dry lignin has $\mathrm{T}_{\mathrm{g}}$ at $130-205^{\circ} \mathrm{C}$. As a result, the $\alpha$-peak of a wood temperature scan may be considered to be the $\mathrm{T}_{\mathrm{g}}$ of lignin in some studies.

The importance of moisture content in the comparison of DMA results between species means that conditioning to common moisture content was central to this study, and $20^{\circ} \mathrm{C}$ and $65 \%$ r.h. (relative humidity) was selected due to its common use in conditioning static bending test specimens. It was decided to avoid using oven dried wood specimens as differences between oven drying with and without vacuum have revealed that residual moisture may have a significant effect on DMA output (Sugiyama and Norimoto 1996). Previous studies on oven dried wood samples have revealed only the $\alpha$ and $\gamma$ peaks (e.g. Birkinshaw 1986). Every effort must be taken to avoid confusion with other DMA studies reported in the literature which have used water saturated conditions for testing wood, and the $T_{g}$ for wood components is significantly different in this case. Similarly, studies which have used other polar solvents or diluents such as polyethylene glycol to submerge wood provide significant softening or plasticisation effects, and have also been excluded from the scope of this paper.

\section{$\underline{\text { Method }}$}

Four wood species, one softwood and three hardwoods, were selected for this study. Samples from sapwood of each wood were prepared to dimensions of $4.5 \times 2.5 \times 46$ $\mathrm{mm}$ (radial $\mathrm{x}$ tangential $\mathrm{x}$ longitudinal). The species tested were Scots pine (Pinus sylvestris Linn.), Obeche (Triplochiton scleroxylon K. Schum.), Gmelina (Gmelina arborea Roxb.) and Alstonia (Alstonia scholaris L. R. Br.) and useful data on density and properties are presented in Table 2. All samples used in the experiment were selected with straight grain free from any defects (knots).

\section{Table 2 here}


As this study was performed in relation to a larger project utilising a bio-resin based wood modification, all samples were immersed in IMS (industrial methylated spirits, $96 \%$ ethanol) under vacuum for 30 minutes with soaking for two hours at atmospheric pressure. Samples were dried in an oven at $120^{\circ} \mathrm{C}$ ( 24 hours) to mimic the treatment received by resin treated samples. No weight loss was observed in these samples following solvent treatment. The wood samples were stored in a climate chamber at $20{ }^{\circ} \mathrm{C}$ and $65 \%$ relative humidity $(\mathrm{RH})$ until they reached equilibrium moisture content prior to DMA analysis. The moisture content at test is reported in Table 2.

The dynamic mechanical properties of the wood samples were measured using a TTDMA (Triton Technology, Grantham, UK). The storage modulus, loss modulus and loss factor $(\tan \delta$ ) were determined under a sinusoidal load in a three point bending mode with span length of $30 \mathrm{~mm}$. Three frequencies, $0.1,1$ and $10 \mathrm{~Hz}$, were used and a heating rate of $5{ }^{\circ} \mathrm{C} / \mathrm{min}$. Measurements were conducted between $-150^{\circ}$ and $150^{\circ} \mathrm{C}$ temperature, within a heated chamber. This temperature range is typical for a thermal scan of wood, as it captures the main relaxation events relating to moisture in wood, and molecular motions (Sugiyama et al. 1998), although more recently some researchers have used lower finishing temperatures to avoid moisture loss effects above room temperature (Li et al. 2018).

Specimens were weighed and measured immediately prior to loading to the DMA, and clamped into the test equipment as soon as possible after transfer from the climate chamber to avoid moisture content change. The specimens were cooled rapidly by liquid nitrogen to the start temperature. The moisture content of the conditioned untreated wood was ca. 8-9\% for the four wood species. A minimum of 3 specimens per species were tested, and seven replicates used for Scots pine. The mean value of storage modulus at room temperature was calculated as well as the relaxation peaks $\beta_{1}, \beta_{2}$ and $\gamma$ of the untreated wood. No $\alpha$-peaks were determined, however a clear upward trend in $\tan \delta$ was observed indicating that this peak lay above $150^{\circ} \mathrm{C}$.

\section{$\underline{\text { Results }}$}

Example graphical representations of the DMA temperature scans of unmodified Scots pine, Obeche, Gmelina and Alstonia wood are presented in Figure 1 (a to d). Although the selected DMA outputs shown in Figure 1 represent the values from single sample runs, the values and trends seen in the other two samples of the same treatment were very similar. The mean value of the three samples tested per treatment per wood species are used in measuring the relaxation events for the wood samples based on peaks in tan $\delta$ (Table 2), and calculating the storage modulus $\left(E^{\prime}\right)$ at room temperature (Table 3 ).

Three relaxation events are clearly visible in Figure 1a for Scots pine, labelled $\beta_{1}, \beta_{2}, \gamma$ from right to left. In the case of Obeche and Gmelina (Figure $1 \mathrm{~b}$ and $\mathrm{c}$ ) the $\beta$ peak was complex, with some overlap of constituent peaks making identification of individual peaks less clear. However, on examination of the $0.1 \mathrm{~Hz}$ data for Gmelina the presence of three peaks is clear within the range 5 to $80^{\circ} \mathrm{C}$ (Figure 1c). Data was not sufficiently close spaced to allow deconvolution of the peaks by software. For Alstonia (Figure 1d), the $\tan \delta$ output from the $0.1 \mathrm{~Hz}$ run also showed the three peaks clearly, but higher frequency runs led to overlap. Numeric values for the identified peaks are reported in Table 2. 


\section{Figure 1 here}

\section{Figure 2 near here}

The DMA plot for Scots pine is typical of softwoods, with a slow decrease in storage modulus but distinct peaks in loss modulus (Figure 1a), and three clear relaxations occurring in the tan $\delta$ graph (Figure 2a). These have been labelled $\beta_{1}, \beta_{2}$ and $\gamma$, from right to left, with $\beta_{1}$ and $\beta_{2}$ relating to rotational motion of saccharide rings in the presence of moisture in the different hemicellulosic components of the wood, and $\gamma$ relating to methylol groups and hydroxymethyl groups in non-crystalline regions of the cellulose or hemicellulose (Obataya et al. 2001, Backman and Lindberg 2001, Havimo 2009, Sharma et al. 2015, see Table 1). The glass transition temperature $\left(\mathrm{T}_{\mathrm{g}}\right)$ of lignin falls outside the measured range for wood at the moisture content used in this experimental work (8\%). Back and Salmén (1982) reported that the $\mathrm{T}_{\mathrm{g}}$ of lignin was not suppressed below 115 to $100^{\circ} \mathrm{C}$ (depending on lignin type) even at high moisture contents. In solid wood at similar moisture content values the glass transition temperature is reported to occur above $200^{\circ} \mathrm{C}$, for example Scots pine $234^{\circ} \mathrm{C}$ (Startsev et al. 2007). Therefore all visible peaks in $\tan \delta$ are interpreted as secondary relaxations.

In Scots pine (Figure 2a), the $\beta_{1}$ peak was observed to decrease in temperature as frequency increased. The average values for seven scans were $58.2,55.6$ and $52.9^{\circ} \mathrm{C}$ when tested at frequencies of $0.1,1$ and $10 \mathrm{~Hz}$ respectively. Figure 3 shows the scatter plot of the $\beta_{1}, \beta_{2}$ and $\gamma$ peaks for the seven samples of Scots pine tested. It is clear that sample to sample variation is considerable. This may partly relate to the low sampling interval used during the temperature scan.

The $\beta_{2}$ peak on the $10 \mathrm{~Hz}$ scan was overlapping with the $\beta_{1}$ peak, but can be seen to have increased in temperature relative to the lower frequency scans, (average values of $21.2,20.7$ and $31.9^{\circ} \mathrm{C}$ were observed for $0.1,1$ and $10 \mathrm{~Hz}$ respectively). In the lower temperature range, the trend for the $\gamma$ peak to increase with frequency was readily visible (Figure 3c). The average temperature values of the $\gamma$ peak for seven scans were $-101.8,-95.2$ and $-82.7^{\circ} \mathrm{C}$ when tested at $0.1,1$ and $10 \mathrm{~Hz}$ frequency respectively. The $\beta_{1}$ peaks shifted from higher temperature to lower temperature when the applied frequencies were increased from 0.1 to $10 \mathrm{~Hz}$. However, the inverse trend was found in the case of the $\beta_{2}$ and $\gamma$ peaks.

\section{Figure 3 near here}

In the hardwood $\tan \delta$ plots (Figure $2 b-d$ ), a slightly different set of relaxations occur, with a greater degree of overlap, especially of peaks within the $\beta$ region. The most notable aspect however is that three peaks appear to occur between $20^{\circ}$ and $60^{\circ} \mathrm{C}$ for the hardwoods. These were consistently observed on all samples of each species of hardwood tested. Values shown in Table 3 are the average of peaks observed in three DMA runs per wood type. Analysis of the loss modulus curve for each individual sample confirmed the observations seen in $\tan \delta$, i.e. that these three events were distinct occurrences. 
In some cases the overlap of $\beta$ peaks in individual $\tan \delta$ graphs made identification of temperature for each event was difficult. For example in the case of Obeche the $\beta_{1}$ and $\beta_{2}$ peaks overlap, making precise determination of peak values difficult (deconvolution of peaks was not considered viable on data of this resolution). Values for all $\tan \delta$ events for all species are indicated in Table 3. 


\section{Table 3 here}

For the hardwood timbers it was observed that as test frequency increased, the location of $\tan \delta$ peaks decreased for the $\beta_{1}$ peak, and in most cases also for the $\beta_{2}$ peak. The $\beta_{2}$ peak of Alstonia moved to higher temperature with increased test frequency, a phenomenon which has not to our knowledge been reported or discussed previously. Similarly, the $\beta_{3}$ peak of all hardwoods tended to increase with increased frequency.

For all species, the $\gamma$ peak moved to higher temperatures as frequency increased. This is the typically expected behaviour for peaks in $\tan \delta$ (Turi 1997), similarly higher frequencies lead to a decrease in intensity of peak, as was seen in these experiments. The $\gamma$-peak is attributed to rotational motion of pendant $\mathrm{CH}_{2} \mathrm{OH}$ groups on the polysaccharide components (hemicellulose and amorphous cellulose) and such motions typically generate a secondary loss peak in DMA analysis.

The moisture content of all samples tested in this study was in the range 8 to $9 \%$, and all samples had been conditioned at $20^{\circ} \mathrm{C}$ and $65 \%$ r.h. prior to testing. Despite this, the location of the three $\tan \delta$ peaks varied between species. Kelley et al. (1987) reported that the glass transition temperature as well as its intensity is dependent on the nature of wood constituents as well as the concentration of water within them.

\section{$\underline{\text { Discussion }}$}

In this study, the chosen softwood is Scots pine, which has been previously studied in DMA by Birkinshaw et al. (1986), Backman and Lindberg (2001), and Startsev et al. (2017). Of the three tropical hardwoods studied (Gmelina, Obeche and Alstonia), few references to DMA experiments were found in the literature. Obeche was included in the Birkinshaw et al. (1986) study, and a different species of Alstonia (Pulai) was included in a study by Islam et al. (2012b), which compared the unmodified wood with wood that had been impregnated with phenolic resin. The moisture content at time of DMA test was not recorded for the Pulai or other tropical hardwoods tested by Islam et al. (2012b), however variation in location of $\tan \delta$ peaks between samples of Jelutong (Dyera costulata), Terbulan (Endospermium diadenum), Batai (Paraserianthes moluccana), Rubberwood (Hevea brasiliensis) and Pulai (Alstonia pneumatophora) were evident. This observation is consistent with the emerging trend in this current work, for the location of $\beta$ and $\gamma$ relaxation events to occur at different temperatures in different wood species, even when conditioned under matching temperature and relative humidity and evaluated on the same DMA apparatus.

Obeche and Scots pine were both studied by Birkinshaw et al (1986) alongside various tropical hardwoods, with a great range of $\tan \delta$ responses observed in a shear modulus study on oven dried wood. As a result of using oven dried wood, the $\tan \delta$ output reported by Birkinshaw et al (1986) showed only minor or no $\beta$ peaks, whereas the $\gamma$ peak at -60 to $-40^{\circ} \mathrm{C}$ was visible in all cases, and an upward trend towards an $\alpha$ peak above $150^{\circ} \mathrm{C}$ (the limit of the temperature range studied) was also apparent. By contrast, the use of timber samples which had been conditioned to a moisture content of 8-9\% for Obeche and Scots pine within this study meant that both showed clear $\beta$ - 
peaks relating to interaction of moisture with the hemicellulosic portion of the wood. In fact in many cases this peak had two components. It is on this basis that we have proposed that the $\beta_{1}$ and $\beta_{2}$ peaks may be differentiated, and in the case of Obeche, a $\beta_{3}$ peak appears also to occur. It is noted that this distinction was most visible at low frequencies, i.e. $0.1 \mathrm{~Hz}$.

It is important to understand the contribution of the individual wood polymers (amorphous cellulose, hemicellulose and lignin) to the dynamic mechanical behaviour of wood. As mentioned earlier, each amorphous component of wood exhibits thermal transitions and relaxations, however the crystalline cellulose will not demonstrate these effects. The glass transition temperature $\left(\mathrm{T}_{\mathrm{g}}\right)$ is the best known, and relates to the transition from the glassy to a rubbery state with a corresponding large decrease in storage modulus. Among the wood polymers the $\mathrm{T}_{\mathrm{g}}$ for lignin is the most commonly studied event detectable by DMA, however this is often observed in water-soaked wood samples evaluated for the pulping industry. In this experiment on wood at a moisture content of 8 to $9 \%$ the $\mathrm{T}_{\mathrm{g}}$ of lignin is likely to occur just above the tested temperature range. The $\mathrm{T}_{\mathrm{g}}$ values for hemicellulose and amorphous cellulose are both reported to occur at high temperature (Back and Salmén 1982), and will fall outside the range of this experiment. When the polymeric substances of wood are studied in situ, there can be differences in interpretation of which component(s) contribute to the $\mathrm{T}_{\mathrm{g}}$ event, which is typically a single peak in $\tan \delta$ above $200^{\circ} \mathrm{C}$ (for conditioned wood). Startsev et al. (2017) demonstrated $\mathrm{T}_{\mathrm{g}}$ of wood in the range 207 to $216^{\circ} \mathrm{C}$ for various temperate hardwood species, and at $234^{\circ} \mathrm{C}$ for Scots pine. The secondary relaxations of the hemicellulose and the effect of moisture acting as a plasticiser within the hemicellulose contribute the relatively small peaks in $\tan \delta$, which are associated with a small loss in storage modulus.

Table 1 showed typical ranges reported in the literature for the various tan $\delta$ events, and Table 3 reported the mean value of observed $\tan \delta$ peaks at each frequency, for the four wood species tested in this study: Scots pine, Obeche, Gmelina and Alstonia. This revealed that two tan $\delta$ peaks occur in the temperature range between 20 to $80{ }^{\circ} \mathrm{C}$ which is typically related to $\beta$ peaks, and one tan $\delta$ peak occurs in lower temperature between -115 to $-90{ }^{\circ} \mathrm{C}, \gamma$ peak. However, while the tan $\delta$ plot was increasing up to $150^{\circ} \mathrm{C}$, no peak value for this highest temperature $\tan \delta$ event ( $\alpha$ peak) could be determined.

In this study all the wood species tested showed a $\tan \delta$ peak, known as the $\gamma$ peak at low temperature range occurring at -90 to $-115^{\circ} \mathrm{C}$ depending on wood species and applied frequency. The tan $\delta$ peak in this temperature range is also reported by many workers and attributed to methylol side chains within the amorphous regions of the polysaccharide components of wood (hemicellulose and amorphous cellulose), possibly coupled with water molecules. Backman and Lindberg (2001) found a $\tan \delta$ peak at $-80^{\circ} \mathrm{C}$ of Scots pine wood in both the radial and tangential direction when tested in $1 \mathrm{~Hz}$ frequency, which is associated due to the movement of the methylol groups coupled with water molecules. Kelley et al. (1987) found a tan $\delta$ peak in the low temperature range between -90 and $-110{ }^{\circ} \mathrm{C}$ for Spruce and Maple wood at $10 \%$ moisture content. It was explained that this behaviour of transition at low temperatures is due to the secondary dispersion involving only small scale molecular motion. 
Maeda and Fukada (1987) claimed that the peak at $-105^{\circ} \mathrm{C}$ for dry wood is due to the movement of the methylol side chain. In this study the $\gamma$ peak occurred between -90 to $-115^{\circ} \mathrm{C}$ for all of the wood species and frequencies studied. It is associated with the methylol groups of the wood polymers and wood polymers and water complexes formed between these functional groups and water.

The $\beta$ peaks are the most susceptible to moving to higher or lower temperature with different moisture content of any wood sample, as it relates to the plasticising effect of water within the hemicellulose fraction, as previously observed by Kelley et al. (1987). For example, the $\beta$ peak was reported to move from -40 to $80{ }^{\circ} \mathrm{C}$ when moisture content increased to $8 \%$ due to the increased motion of chain segment and the complex of wood polymers and water (Backman and Lindberg, 2001). However in this experiment the three frequencies were run on the same sample within the same run, so moisture content differences can play no part in the observed difference. In multifrequency studies, it would most commonly be expected that the difference in observed temperature of $\tan \delta$ events relates to the quantity of energy required to instigate that molecular motion within the sample, this follows an Arrhenius relationship (Björkman and Salmén 2000). Higher frequencies are related to higher energy input requirements, so transitions or relaxations for higher frequency scans typically occur at higher temperatures. Conversely, lowering the frequency typically shifts relaxations to lower temperatures (Menard and Menard 2015).

The observations of $\beta$ peak locations within this study poses greater questions. The fact that $\beta_{1}$ occurred at a decreased temperature, with a decrease in peak intensity, for increased frequency, does not conform to the classical model of secondary loss peaks. However, it is known that the $\beta$-peaks relate to moisture (within the amorphous polysaccharide components) and that a plasticising action has been proposed. The presence of a plasticiser does not directly lead to a change in temperature of the secondary maxima seen in $\tan \delta$, however stereochemical factors (such as side group size, bulkiness of the monomer units within the chain, and their resulting mobility), do alter the temperature of these relaxation peaks. In the case of hemicellulose this may relate to the single or multi-sugar units pendant on the main chain, or to the specific combination of sugar monomers within the chain backbone. Extent of hydrogen bonding will also play a significant role in determining segment mobility, and the increase in moisture content will facilitate rearrangements which are not possible in the fully dry state.

In one study of the rheological properties of substituted celluloses, a complex set of behaviours were reported, relating not only to the level of substituted units per available anhydroglucose unit on the cellulose, but also the number of hydroxyethyl monomers per individual unit. Both factors altered the temperature of $\beta$ peaks, however moisture content had the additional effect of introducing a second $\beta$ peak which was not present in dried samples, which was attributed to frozen or bound water within the sample (Kim et al. 1991). In DMA studies on amorphous cellulose $\beta$ and $\gamma$ peaks are seen, with the $\beta$ peak being either the interaction of hydroxymethyl groups with water or the motion of main chain segments, and Montes et al. (1997) report that this aspect has not yet been resolved. During their investigation of the effect of temperature and moisture loss on the $\beta$ peak, they revealed a complex evolution process for the $\beta$ relaxation, with the activation energy for this peak changing on each thermal step. They concluded that the $\beta$ relaxation demonstrated 
cooperativity from either intramolecular or intermolecular contributions. The observations were confirmed and extended by Roig et al. (2001) who used dielectric analysis to demonstrate that the activation energy of cellulose $\beta$ peaks decreases with increased moisture content, i.e. confirming the role of moisture as a plasticiser. By contrast Roig et al. (2001) showed that $\gamma$ peaks for cellulose have activation energy which increases with moisture, and that this relaxation shows anti-plasticity. In the dry state the activation energy for $\gamma$ peaks in cellulose corresponds with the activation energy of a single hydrogen bond $(40 \mathrm{~kJ} / \mathrm{mol})$, and $\beta$ peaks correspond with approx. two hydrogen bonds.

Other pure polysaccharides have been studied by DMA, for example pure 4-Omethylglucuronoxylan is reported to have gamma and beta relaxations at -26 and $80^{\circ} \mathrm{C}$, and these have been reported to move to lower temperatures at increasing moisture contents (Ebringerova and Heinze 2000). The multiple $\beta$ relaxation peaks seen in this study are likely to relate to the greater complexity of segmental motions in the polysaccharide components, cellulose and hemicellulose. The entropy contribution, and the level of cooperativity may vary between these components.

A study on the E' and E' which give rise to this relaxation peak in wood (which had been exposed to three different drying methods, then conditioned to equilibrium moisture contents of $33 \%, 75 \%$ and $93 \%$ ) revealed differences in the level of increase in loss modulus at 34 to $40^{\circ} \mathrm{C}$ which depended on the drying method used (Jiang and $\mathrm{Lu} 2008$ ). The location of these peaks moved to lower temperatures, reaching 3 to $5^{\circ} \mathrm{C}$ as the EMC increased to circa $17 \%$ under the highest relative humidity. For the EMC closest to that used in this current study, the peak occurred at 11 to $17^{\circ} \mathrm{C}$ depending on drying method, and was recorded at $1 \mathrm{~Hz}$. This is consistent with the $\beta_{2}$ peak in Scots pine samples and $\beta_{3}$ peak observed in hardwood samples of this experiment.

It is also possible that lignin has secondary relaxation peaks, which could occur within the studied temperature range. This has been proposed based on dielectric analysis and thermostimulated current analysis (TSC), with a $\beta$ peak for lignin occurring near $70^{\circ} \mathrm{C}$ in the experiments of Roig et al. (2017). By contrast they located $\gamma$ for cellulose at a lower temperature ( $\operatorname{circa}-135^{\circ} \mathrm{C}$ ), and commented that this frequently dominates the lignin $\beta$ peak. The $\beta$ peak for cellulose was seen at higher temperature (circa $65^{\circ} \mathrm{C}$ ). In DMA studies, Placet et al. (2007) used Cole-Cole diagrams to indicate the superposition of two relaxation events, one relating to lignin, and the other to hemicellulose, however this was in green wood tested wet. Data plotted by Engelund et al. (2013) indicated a relationship between softening point of hemicellulose, temperature and relative humidity, and led to considering the relation of sorption hysteresis with the glass transition temperature. Startsev et al. $(1999,2017)$ concluded that between room temperature and $70^{\circ} \mathrm{C}$ several peaks are superimposed, including the local mobility of cellulose chains, the glass transition of "its amorphous part the lignin" and the hemicelluloses plasticised by water. Studies on pure glucomannan and xylan films by Kulasinski et al. (2016) have further confirmed the complexity of dynamic mechanical response of hemicellulose in atmospheres of varying relative humidity. In dielectric analysis of polysaccharides a complex response has been indicated, with an additional secondary relaxation ( $\left.\beta_{\text {wet }}\right)$ occurring under certain conditions relating to moisture state (Shinouda and Moteleb 2005, Zhao et al. 2019). 


\section{Chemical composition effects}

A clear difference in the location of the $\beta_{1}$ and $\beta_{2}$ peaks is seen for the softwood, Scots pine, compared to the hardwood species (Table 3). It is known that hardwood hemicellulose composition is significantly different from softwoods, with a high proportion of methylglucuronoxylans in hemicellulose of hardwoods, compared to the galactoglucomannan rich softwood hemicellulose (Sjöström 1993). In addition glucomannans are present in both hardwoods and softwoods, and a number of other hemicellulose forms are seen in softwoods, including arabinoglucuronoxylan, arabinogalactan, xyloglucan and other glucans, as well as pectins (Laine 2005). It is expected that the type and location of different hemicelluloses within the wall will have an influence on moisture interactions and viscoeleastic response seen in DMA analysis.

In softwoods, there is a strong association between cellulose and glucomannan, while in hardwoods the xylans occur in both low-substituted and high-substituted forms, with the low-substituted form being deposited first in the cell wall formation, i.e. closer to the cellulose aggregates (Salmén and Burgert 2009). Models for the lenticular arrangement of amorphous regions between crystalline aggregates within the $S_{2}$ layer of the cell wall have been proposed in which the glucomannan (in softwoods) forms a layer nearest the cellulose, with inner regions of condensed lignin, xylan and uncondensed lignin (Salmén and Burgert 2009, Åkerholm and Salmén 2003). The effect of the association of glucomannan with cellulose in spruce fibres was studied with dynamic FT-IR spectroscopy, indicating a high degree of alignment in the glucomannan spectra, indicating co-orientation with the cellulosic microfibrils (Åkerholm and Salmén 2001).

In hardwoods the different hemicellulose composition and high affinity for lowsubstituted xylans with the cellulosic regions, is expected to result in a different set of relaxation responses in the $\beta$-peak region. In a later study by Åkerholm and Salmén (2004) the influence of moisture was investigated for spruce and birch pulps. Moist $\left(40^{\circ} \mathrm{C}\right.$ and $95 \%$ r.h. $)$ and dry $\left(25^{\circ} \mathrm{C}\right.$ and $0 \%$ r.h. $)$ conditions were compared, and a small increase of viscoelasticity observed. This was ascribed primarily to the effect of water on lignin, but also water on hemicellulose. Dielectric and DMA analysis by Roig et al. (2017) indicated differences between three hardwood timbers, which were attributed to the molecular mobility, due to the modifying effect of the specific environment within woods of differing macromolecular arrangement.

Hemicellulose composition for tropical wood species is under-reported, and in the extensive review by Pettersen (1984) only Obeche is relevant to this study. For Obeche and Scots pine the Cross and Bevan cellulose was $49 \%$ and 54\% respectively, pentosans $19 \%$ and $11 \%$ respectively, and Klason lignin $33 \%$ and $28 \%$ respectively. However no breakdown of the dominant hemicellulose polymers is given. Other more recent studies have also included only Obeche (Nuöpponen et al. 2006, Fabiyi et al. 2011) from the three tropical timbers used in our present study. Fabiyi reported variation in both syringyl-guaiacyl ratio of lignin, and hemicellulose composition, based on FTIR data variability between seven hardwood species. PCA analysis for FTIR for 25 tropical hardwoods by Nuöpponen et al. (2006) showed substantial variability in lignin structures, tannins and xylan content, however the only direct data for Obeche presented was the acetyl bromide lignin content $(28.5 \%)$ and $\alpha$-cellulose 
content (38.5\%), with $1.3 \%$ acetone-soluble extractives (Nuöpponen et al. 2006). The extractive content in some tropical hardwood species can be significant (Nuöpponen 2006), and may influence moisture sorption and equilibrium moisture content of the wood. Extractives have also been indicated to alter the results of DMA studies (Se Golpayegani et al. 2011). However, the use of sapwood of all four test species will limit the extractive content, and the alcohol preparation step, may have further limited the influence of extractives in this study. Average values for tan $\delta$ events for each frequency have been presented in Table 3, allowing comparison of the effect of test frequency and species.

It is increasingly recognised that location of different hemicelluloses adjacent to cellulosic microfibrils is dependent on the molecular structure of the hemicellulose, and has a strong influence on stiffness and viscoelasticity of the cell wall (Carpita and Gibeaut 1993, Cosgrove and Jarvis 2012). For example in softwoods the epitaxial alignment of xylan alongside the cellulose will lead to this xylan slotting together on a two-fold helical screw (Simmons et al. 2016). Glucomannans also have an affinity for the cellulose of the microfibril aggregates, and are proposed to occupy the space between these xylan-coated microfibrils, providing flexible bridges between exposed sections of cellulose (Cosgrove and Jarvis 2012). The hemicellulose distribution within hardwood cell walls is less studied, and such studies are primarily on temperate species or Eucalypts for pulp manufacture. Differences in both hemicellulose composition, and its distribution in the three hardwoods of this study are anticipated, given the diversity of xylem tissue anatomy in this class of timbers. Indications that hemicellulose accessibility varies significantly between tropical hardwood timbers is found in the thermogravimetric analysis by Fabiyi et al. (2011), who indicated that the sequence of decomposition of xylans, mannans then lignin and cellulose in Obeche started at lower temperature for Obeche than other species studied. This may relate to accessibility, as degradation rate was also high. Further research in this area, including chemical analysis, is required.

Moisture is responsible for the relaxations detected as $\beta$ peaks, which show the greatest degree of variability between the four species, as seen in Figure 2. As the hemicellulose regions are recognised as being the most easily accessed by moisture, and the formation and re-formation of hydrogen bonds between hemicellulose and water occurs in a constant state of flux driven by environmental conditions, the effect of differences in hemicellulose composition and arrangement within the timbers is expected to have contributed to the differences seen. The Gmelina and Alstonia woods showed further diversity of $\tan \delta$ peaks in the $\beta$ range (Figure $2 \mathrm{c}, \mathrm{d}$ ), illustrating the species dependence of behaviour. In addition to the absolute hemicellulose composition, and the location of the hemicellulose within the framework of cellulosic fibril aggregates in the cell wall, the accessibility to moisture should be considered. If low-substituted xylans are assumed to have closest affinity with the cellulosic regions on the surface of the aggregates, with high-substituted xylans and other hemicelluloses in the centre of the lenticular regions (along with condensed and non-condensed lignin), it could be assumed that these two regions show different capacities for moisture uptake, even when wood has been conditioned to equilibrium moisture content. Xylans possess two free hydroxyl groups per xylose unit, whereas glucose and mannose possess three free hydroxyl units, presenting a theoretically greater number of sorption sites in glucomannans (Kulasinski et al. 2016). Studies of wood cell wall hygroscopicity typically consider a relatively 
homogeneous substrate, however in the emerging lenticular model this is far from the case. The transient pores within the hemicellulosic, or amorphous cellulosic, regions may therefore have differing accessibility, and differing activation energies for adsorption of water by hydrogen bond substitution. Studies on films of extracted hemicelluloses (konjac glucomannan and rye arabinoxylan) showed clear differences in dynamic modulus and $\tan \delta$ in studies investigating moisture content (Kulasinksi et al. 2016). This indicates that moisture dependent differences in dynamic properties between hemicelluloses in situ within the wood cell wall are also likely. Further experimental work in this area is clearly needed, coupled with mathematical investigation to test the hypothesis, however the authors propose that this may provide the origin for the multiple $\beta$ peaks observed within this study.

\section{Storage modulus at room temperature}

The DMA test splits the behaviour of wood into an elastic component (storage modulus, E') and a viscoelastic component (loss modulus, E'"). Here the dynamic modulus $E^{*}$ can be defined, as shown in Equation 1. The Modulus of Elasticity in static bending tests would be measured under different conditions, usually calculated over a much larger portion of the load deflection graph than that used in DMA analysis (which must be conducted within the linear viscoelastic range, Sun et al. 2007).

$\mathrm{E}^{*}=\mathrm{E}^{\prime}+\mathrm{iE}$,

Where $i$ is the square root of -1 .

As E', is of much smaller magnitude than E', it can be generally assumed that a higher storage modulus (E') value indicates a higher modulus of elasticity of the material. The storage modulus recorded by DMA at a given temperature can therefore give insight into the mechanical properties, for example at normal working conditions $\left(20^{\circ} \mathrm{C}\right)$.

The E' of the different wood species was measured from the E' curve over the temperature scan at room temperature $\left(20-25^{\circ} \mathrm{C}\right)$. The mean $\mathrm{E}$ ' value at room temperature for Scots pine, Obeche, Gmelina and Alstonia seen at different frequencies are presented in Table 4. It was noted that the storage modulus values were lower than those expected for these species from static bending tests on small clear samples (Table 2). A typical MOE for Scots pine in 3-point bending under static load is $10 \mathrm{GPa}$ at $12 \%$ moisture content (Lavers 1969), while the MOE for Gmelina and Obeche are reported as 6.3 GPa and 5.5 GPa respectively. For a different species of Alstonia, Alstonia boonei (from Uganda) the MOE is $8.3 \mathrm{GPa}$. The difference between static bending tests and the values shown in Table 4 relates to the measurement being taken in the earliest portion of the load deflection curve (which is commonly excluded from MOE calculations) and the difference between static and dynamic measurement systems.

\section{Table 4 here}

The data for the four wood species demonstrates clearly that the E'values are altered by the test frequency, with higher frequencies resulting in a greater storage modulus. This effect of frequency correlates well with the well known tendency for MOE to 
increase with the rate of loading in static bending tests. This comparison of storage modulus with MOE from static bending tests has been included to highlight the need for great caution in utilising storage modulus data to derive MOE values.

Species difference is indicated, with Scots pine being the stiffest of the four species tested. Among the hardwoods Gmelina was stiffest, Alstonia next and Obeche the least. It is therefore possible to confirm that the ranking of species by stiffness when measured by DMA (using E') does compare well with the ranking achieved using static bending tests to derive MOE.

\section{$\underline{\text { Conclusions }}$}

Dynamic mechanical analysis is a useful technique for probing the viscoelastic properties of wood. The relative contribution of cellulose, hemicellulose and lignin to this behaviour are becoming better understood, and the contribution of bound water acting as a plasticiser within the wood depending on moisture content can be detected using the DMA technique. The hydrophobicity, or reduced uptake of moisture, is also an important consideration in modified woods, so DMA has much to offer ongoing research into wood modification.

Within this study, four species of similar density were compared, and significant differences in the location of $\tan \delta$ peaks were shown. The appearance of multiple peaks within the $\beta$ region of the temperature range prompted the attribution of peaks to be revisited, and discussion of the possibility for multiple relaxation events relating to different hemicellulose components in the wood. It is proposed that the different hemicellulose polysaccharides have differing mobility and accessibility to moisture, resulting in multiple relaxation events within the range from 20 to $70^{\circ} \mathrm{C}$. The differences are proposed to relate to steric hindrance within specific polysaccharide regions of the cell wall, and the resulting effect on plasticisation effects of this moisture in the different chemical environments within the cell wall. The proportion and distribution of lignin and lignin carbohydrate complex may also contribute to the variation seen in the different wood species.

In particular, the cell wall ultrastructure, and the intimate association of the xylanbased hemicellulose polymers with the more crystalline cellulose, and the location of hemicelluloses with mannan-dominated backbones as a matrix material, will affect the viscoelastic behaviour of these amorphous regions. These differences will also govern the capacity for moisture migration into these distinct regions of the cell wall. This may lead to considerable difference in viscoelastic behaviour of the cell wall unit. Modern research into plant science has proposed a plasticised, viscoelastic behaviour of certain hemicelluloses and pectins in regulating cell expansion during plant growth, and the inhibition of this motion which is necessary for turgor pressure inside the cell to be maintained without further expansion on maturity. A search of literature revealed little information on the chemical composition of the tropical species used within this study, which would be required to support further discussion. Further work in this area requires hemicellulose composition of the four species to be determined. 


\section{$\underline{\text { References }}$}

Åkerholm M. and Salmén L. (2001) Interaction between wood polymers studied by dynamic FT-IR spectroscopy. Polymer 42:963-969.

Åkerholm M. and Salmén L. (2003) The oriented structure of lignin and its viscoelastic properties studied by static and dynamic FT-IR spectroscopy.

Holzforschung 57:459-465.

Åkerholm M. and Salmén L. (2004) Softening of wood polymers induced by moisture studied by dynamic FTIR spectroscopy. Journal of Applied Polymer Science 94:20322040 .

Ashaduzzaman Md., Hale M.D., Tverezovskiy V. and Ormondroyd G.A. (2013) Effect of bio-resin from cashew nut shell liquid (CNSL) on decay resistance properties of wood. IRG working paper, $44^{\text {th }}$ Annual Meeting of the International Research Group on Wood Protection, Stockholm, Sweden, 16-20 June 2013. IRG/WP 13-40649, 15pp.

Back E.L. and Salmén L. (1982) Glass transitions of wood components hold implications for molding and pulping processes. TAPPI 65(7):107-110.

Backman AC and Lindberg KAH (2001) Differences in wood material responses for radial and tangential direction as measured by dynamic mechanical thermal analysis. J. Mat Sci 36:3777-3783

Becker H. and Noack D. (1968) Studies in Dynamic Torsional Viscoelasticity of wood. Wood Science and Technology 2:213-230.

Birkinshaw C., Buggy M. and Henn G.G. (1986) Dynamic mechanical analysis of wood. Journal of Materials Science Letters 5:898-900.

Björkman A. and Salmén L. (2000) Studies on solid wood. II The influence of chemical modifications on viscoelastic properties. Cellulose Chemistry and Technology 34:7-20.

Carpita N.C. and Gibeaut D.M. (1993) Structural models of primary cell walls in flowering plants: consistency of molecular structure with the physical properties of the walls during growth. The Plant Journal 3(1):1-30.

Cosgrove D.J. and Jarvis M.C. (2012) Comparative structure and biomechanics of plant primary and secondary cell walls. Frontiers in Plant Science 3:204, 6pp, DOI: 10.3389/fpls.2012.00204.

Ebrahimzadeh P.R. and Kubat D.G. (1993) Effects of humidity changes on damping and stress relaxation in wood. J. Mater Sci. 28:5668-5674

Ebringerova A. and Heinze T. (2000) Xylan and xylan derivatives - biopolymers with valuable properties, I, naturally occurring xylans, structures, isolation procedures and properties. Macromolecular Rapid Communications 21(9):542-546. 
Entwistle K.M. (2005) Mechanosorptive effect in Pinus radiata D. Don. Holzforschung 59:552-558.

Engelund E.T., Thygesen L.G. and Svensson S. (2013) A Critical discussion of the physics of wood-water interactions. Wood Science and Technology 47:141-161.

Fabiyi J.S., Fuwape J.A. and Olufemi B. (2011) Surface chemistry and thermosmechanical analysis of some Nigerian wood species. Thermochimica Acta 524:80-87.

Gerhards C.C. (1982) Effect of moisture content and temperature on the mechanical properties of wood: an analysis of immediate effects. Wood and Fiber 14(1):4-36.

Hadi Y.S., Nurhayati T., Jasni, Yamamoto H. and Kamiya N. (2012) Resistance of smoked wood to subterranean and dry-wood termite attack. International Biodeterioration and Biodegradation 70:79-81.

Havimo M. (2009) A literature-based study on the loss tangent of wood in connection with mechanical properties. Wood Science and Technology 43:627-642.

Heijboer J. (1977) Secondary loss peaks in glassy amorphous polymers. International Journal of Polymeric Materials 6(1-20):11-37.

Hoffman G., Poliszko S. and Hilczer T. (1990) Model approach to dielectric -thermal analysis of wood modified with polymer. Journal of Applied Polymer Science 39(1):153-167.

Holzer S.M., Loferski J.R. and Dillard D.A. (1989) A review of creep in wood: concepts relevant to develop long-term behaviour predictions for wood structures. Wood and Fiber Science 21(4):376-392.

Horvath B., Peralta P., Frazier C. and Peszlen I. (2011) Thermal softening of transgenic aspen. BioResources 6(2):2125-2134.

Islam Md.S., Hamdan S., Jusoh I., Rahman Md.R., Ahmed A.S. (2012a) The effect of alkali pretreatment on mechanical and morphological properties of tropical wood polymer composites. Materials \& Design 33:419-424.

Islam Md.S., Hamdan S., Talib Z.A., Ahmed A.S. and Rahman Md.R. (2012b)

Tropical wood polymer nanocomposite (WPNC): The impact of nanoclay on dynamic mechanical thermal properties. Composites Science and Technology 72:1995-2001.

Jiang J.L. and Lu J.X. (2008) Dynamic viscoelasticity of wood after various drying processes. Drying Technology 26:537-543.

Kelley S.S., Rials T.G. and Glasser W.G.. (1987) Relaxation behaviour of the amorphous components of wood. Journal of Materials Science 22(2): 617-624.

Kim K.Y., Kim N.H. and Nishinari K. (1991) Dielectric and viscoelastic properties of cellulose derivatives. Carbohydrate Polymers 16:189-198. 
Kulasinski K., Salmén L., Derome D. and Carmeliet J. (2016) Moisture adsorption of glucomannan and xylan hemicelluloses. Cellulose 23:1629-1637.

Laine C. (2005) Structures of hemicelluloses and pectins in wood and pulp. Doctoral thesis, Helsinki University of Technology.

Lavers G.M. (1969) The strength properties of timbers. Forest Products Research Bulletin No 50, HMSO.

Li Z., Jiang J. and Lu J. (2018) Moisture-dependent orthotropic viscoelastic properties of Chinese fir wood in low temperature environment. Journal of Wood Science 64: 515-525.

Maeda H. and Fukada E. (1987) Effect of bound water on Piezoelectric, Dielectric and Elastic Properties of Wood. Journal of Applied Polymer Science 33:1187-1198.

Menard K.P. and Menard K.K. (2015) Dynamic mechanical analysis in the analysis of polymers and rubbers. Encyclopedia of Polymer Science and Technology. John Wiley and Sons, Inc. https://doi.org/10.1002/0471440264.pst102.pub2

Montès H., Mazeau K. and Cavaillé J.Y. (1997) Secondary mechanical relaxations in amorphous cellulose. Macromolecules 30:6977-6984.

Nuopponen M.H., Wikberg H.I., Birch G.M., Jääskeläinen A.-S., Maunu S.L., Vuorinen T. and Stewart D. (2006) Characterization of 25 Tropical Hrdwoods with Fourier Transform Infrared, ultraviolet Resonance Raman, and ${ }^{13} \mathrm{C}-\mathrm{NMR}$ CrossPolarization/Magic-Angle Spinning Spectroscopy. Journal of Applied Polymer Science 102:810-819.

Obataya E., Norimoto M. and Tomita B. (2001) Mechanical relaxation processes of wood in the low temperature range. Journal of Applied Polymer Science 81:33383347.

Olsson A.M. and Salmén L. (1992) Viscoelasticity of in situ lignin as affected by structure softwood vs hardwood. ACS Symp Series USA 489:133-149

Pettersen R.C. (1984) The chemical composition of wood. In: Chemistry of Solid Wood, Rowell R. (Ed.) ACS Advances in Chemistry Series 207. Pp57-126.

Placet V., Passard J. and Perré P. (2007) Viscoelastic properties of green wood across the grain measured by harmonic tests in the range $0-95^{\circ} \mathrm{C}$ : Hardwood vs. softwood and normal wood vs. reaction wood. Holzforschung 61:548-557.

Roig F., Dantras E., Dandurand J. and Lacabanne C. (2001) Influence of hydrogen bonds on glass transition and dielectric relaxations of cellulose. J. Phys D-Appl. Phys. 44:045403, 8pp. 
Roig F., Ramanatsizehena G., Razafindramisa F.L., Dantras E., Dandurand J., Hoyet H., Bernes A. and Lacabane C. (2017) Dielectric and mechanical properties of various species of Madagascan woods. Wood Science and Technology 51:1389-1404.

Salmén L. (1984) Viscoelastic properties of in situ lignin under water saturated conditions. Journal of Materials Science 19: 3090-3096.

Salmén L. and Burgert I. (2009) Cell wall features with regard to mechanical performance. A review. Holzforschung 63:121-129.

Se Golpayegani A., Brémaud I., Gril J., Thevenon M.-F., Arnould O. and Pourtahmasi K. (2011) Effect of extractions on dynamic mechanical properties of white mulberry (Morus alba). Journal of Wood Science 58:153-162.

Sharma M., Brennan M., Chauhan S.S., Entwistle K.M., Altaner C.M. and Harris P.J. (2015) Wood quality assessment of Pinus radiata (radiata pine) saplings by dynamic mechanical analysis. Wood Science and Technology 49:1239-1250.

Shinouda H.G., Moteleb M.M.A. (2005) Dielectric spectroscopy and relaxation phenomena of moistened and dry polysaccharides. Journal of Applied Polymer Science 98:571-582.

Simmons T.J., Mortimer J.C., Bernardinelli O.D., Pöppler A.-C., Brown S.P., deAzevedo E.R., Dupree R. and Dupree P. (2016) Folding of xylan onto cellulose fibrils in plant cell walls revealed by solid-state NMR. Nature Communications 7:13902, DOI: $10.1038 /$ ncomms 13902

Sjöstrom E. (1993) Wood chemistry: fundamentals and applications. Academic Press.

Startsev O.V., Salin B.N., Skuridin Y.G. Utemesov R.M. and Nasonov A.D. (1999) Physical properties and molecular mobility of new wood composite plastic $<<$ thermobalite>>. Wood Science and Technology 33:73-83.

Startsev, O. V., Makhonkov, A., Erofeev, V. and Gudojnikov, S. (2017). Impact of moisture content on dynamic mechanical properties and transition temperatures of wood. Wood Material Science \& Engineering, 12(1): 55-62.

Sugiyama M. and Norimoto M. (1996), Temperature dependence of dynamic viscoelasticities of chemically treated woods. Mokuzai Gakkaishi 42(11):1049-1056.

Sugiyama M., Obataya E. and Norimoto M. (1998) Viscoelastic properties of the matrix substance of chemically treated wood. Journal of Materials Science 33:35053510 .

Sun N., Das, S. and Frazier, C. E. (2007). Dynamic mechanical analysis of dry wood: linear viscoelastic response region and effects of minor moisture changes.

Holzforschung 61(1):28-33.

Turi (1997) TA Thermal Solutions Sheet 62 
Wert C.A., Weller M. and Caulfield D. (1984) Dynamic loss properties of wood. Journal of Applied Physics 56:2453-2458.

Zhan T., Jiang J., Lu J. and Peng H. (2015) Dynamic viscoelastic properties of Chinese fir under cyclical relative humidity variation. J. Wood Sci. 61:465-473.

Zhao H., Chen Z., Du X., Chen L. (2019) Contribution of different state of absorbed water to the sub- $\mathrm{T}_{\mathrm{g}}$ dynamics of cellulose. Carbohydrate Polymers 210:322-331 
Dynamic mechanical analysis of Scots pine and three tropical hardwoods Figures

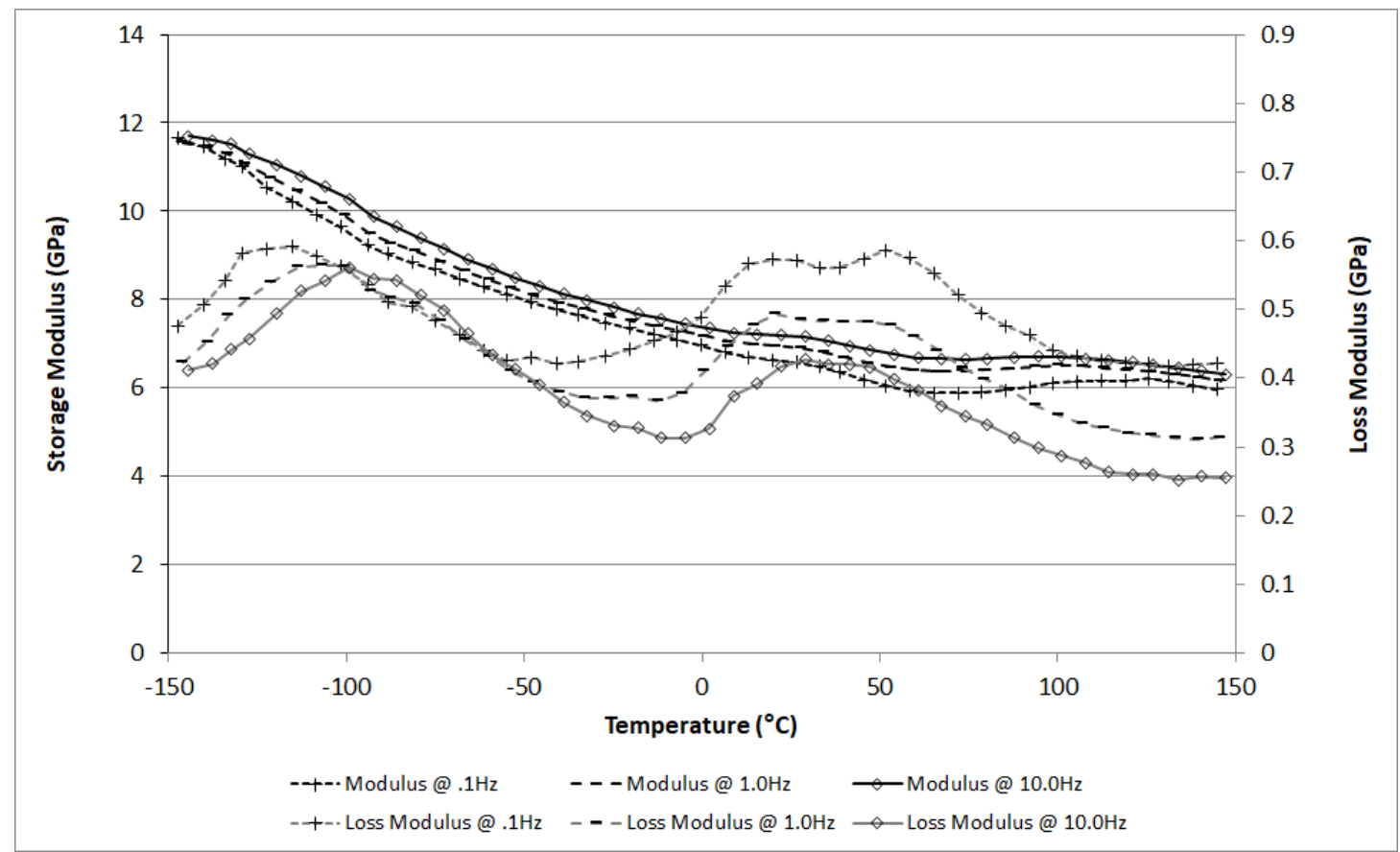

Figure 1a: Storage modulus (E') and loss modulus (E') of a Scots pine (Pinus sylvestris) wood sample.

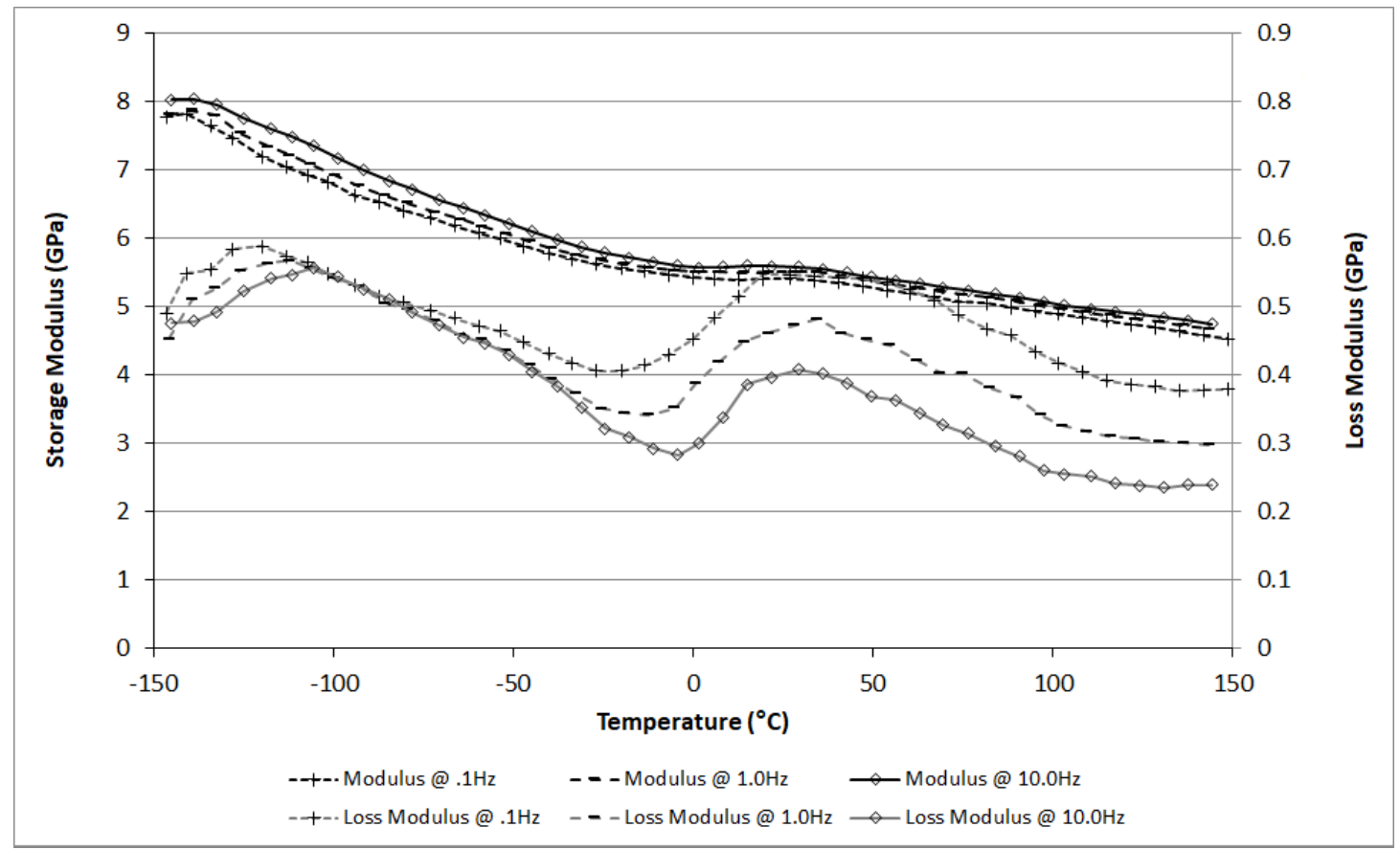

Figure 1b: Storage modulus (E') and Loss modulus (E") of an Obeche (Triplochiton scleroxylon) wood sample. 


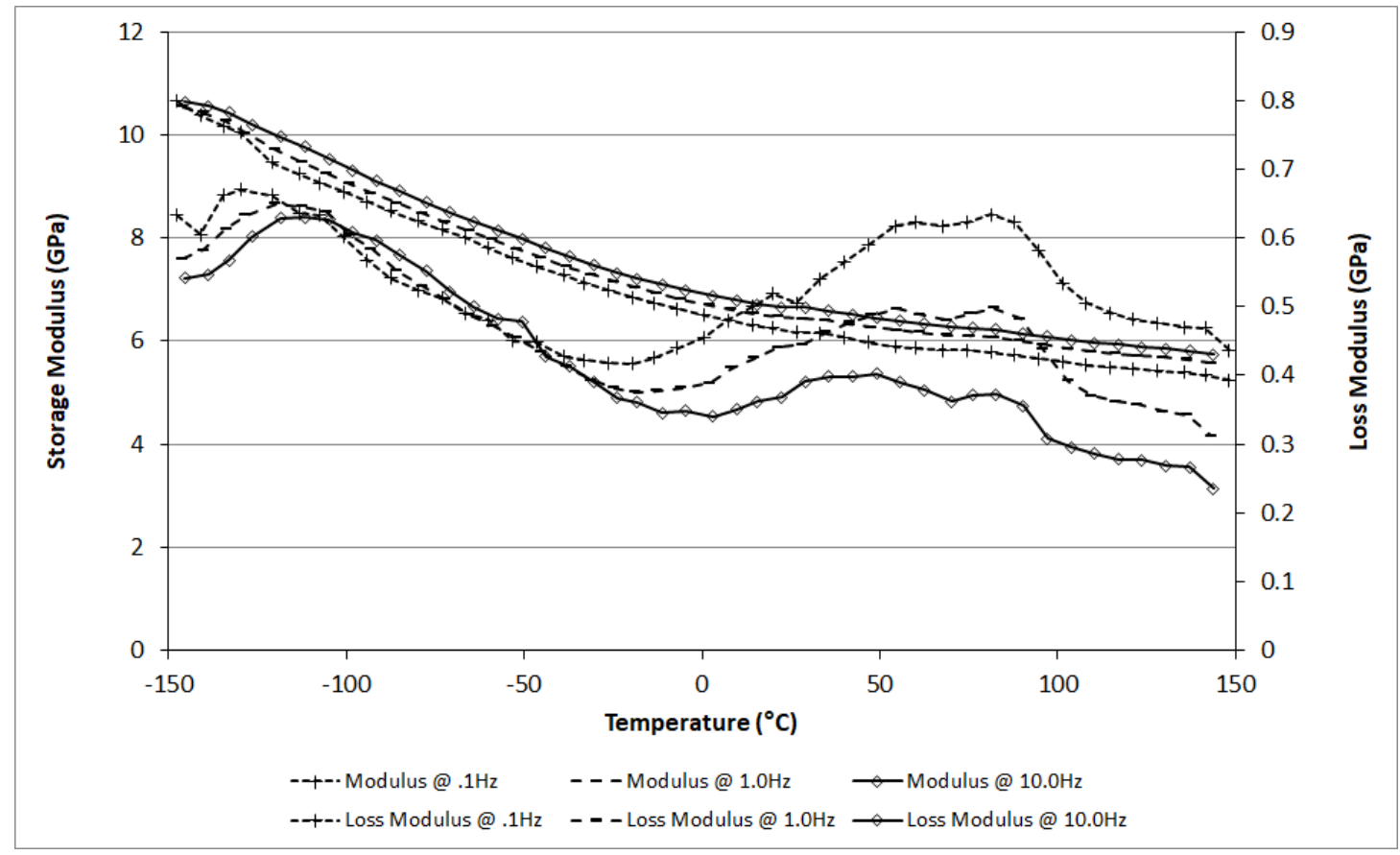

Figure 1c: Storage modulus (E') and Loss modulus (E") of a Gmelina (Gmelina arborea) wood sample.

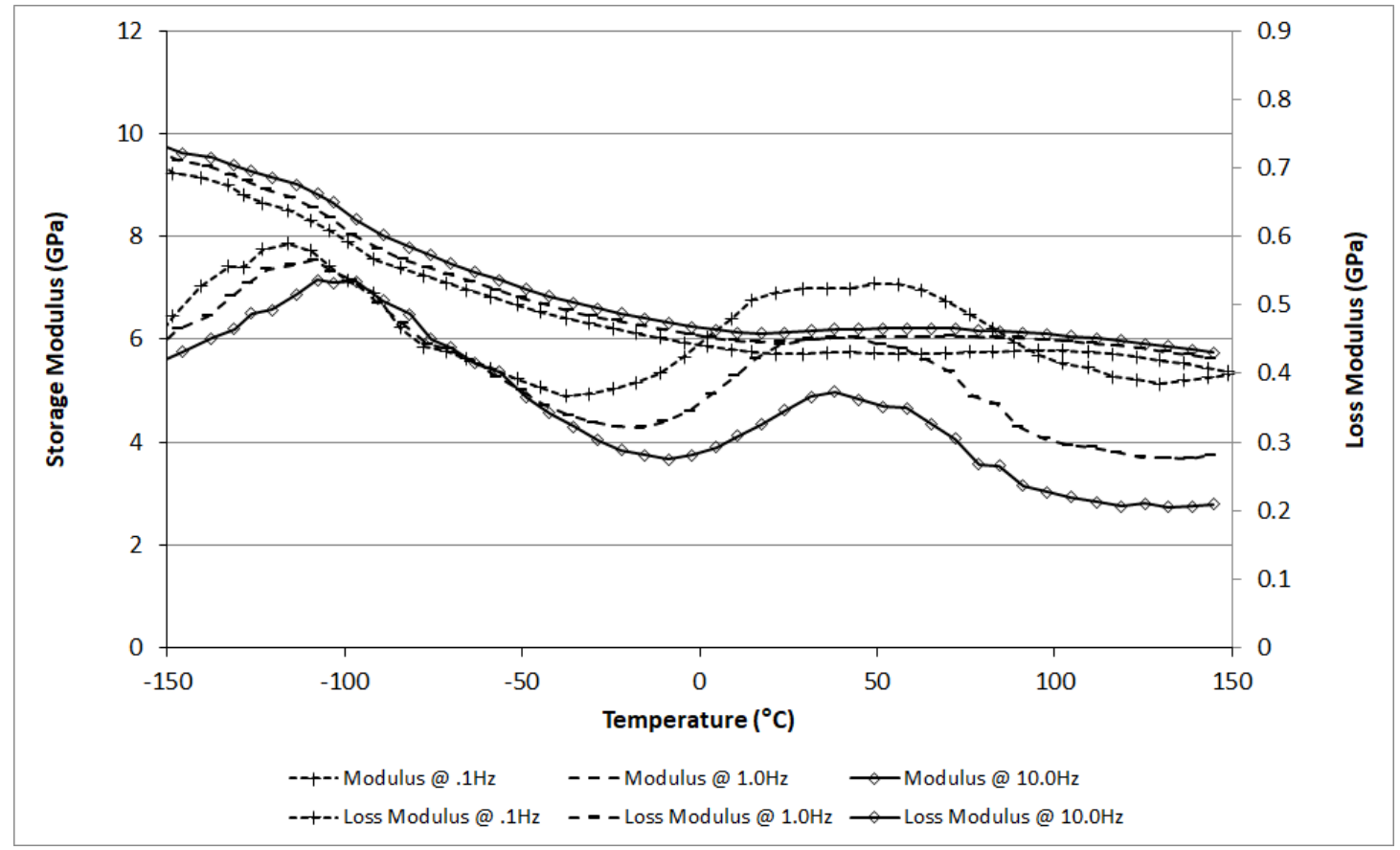

Figure 1d: Storage modulus (E') and Loss modulus (E") of an Alstonia (Alstonia scholaris) wood sample. 
a)

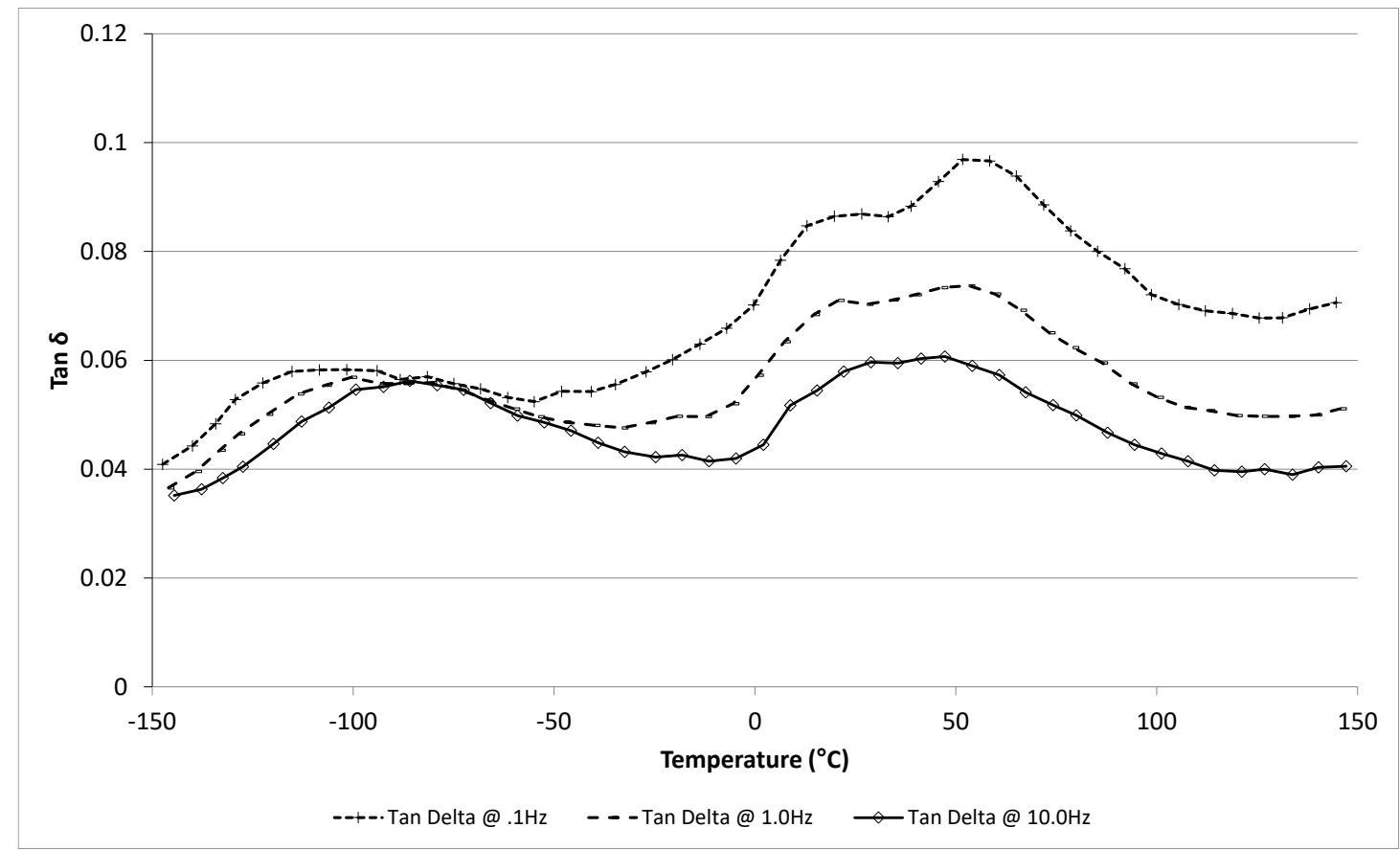

b)

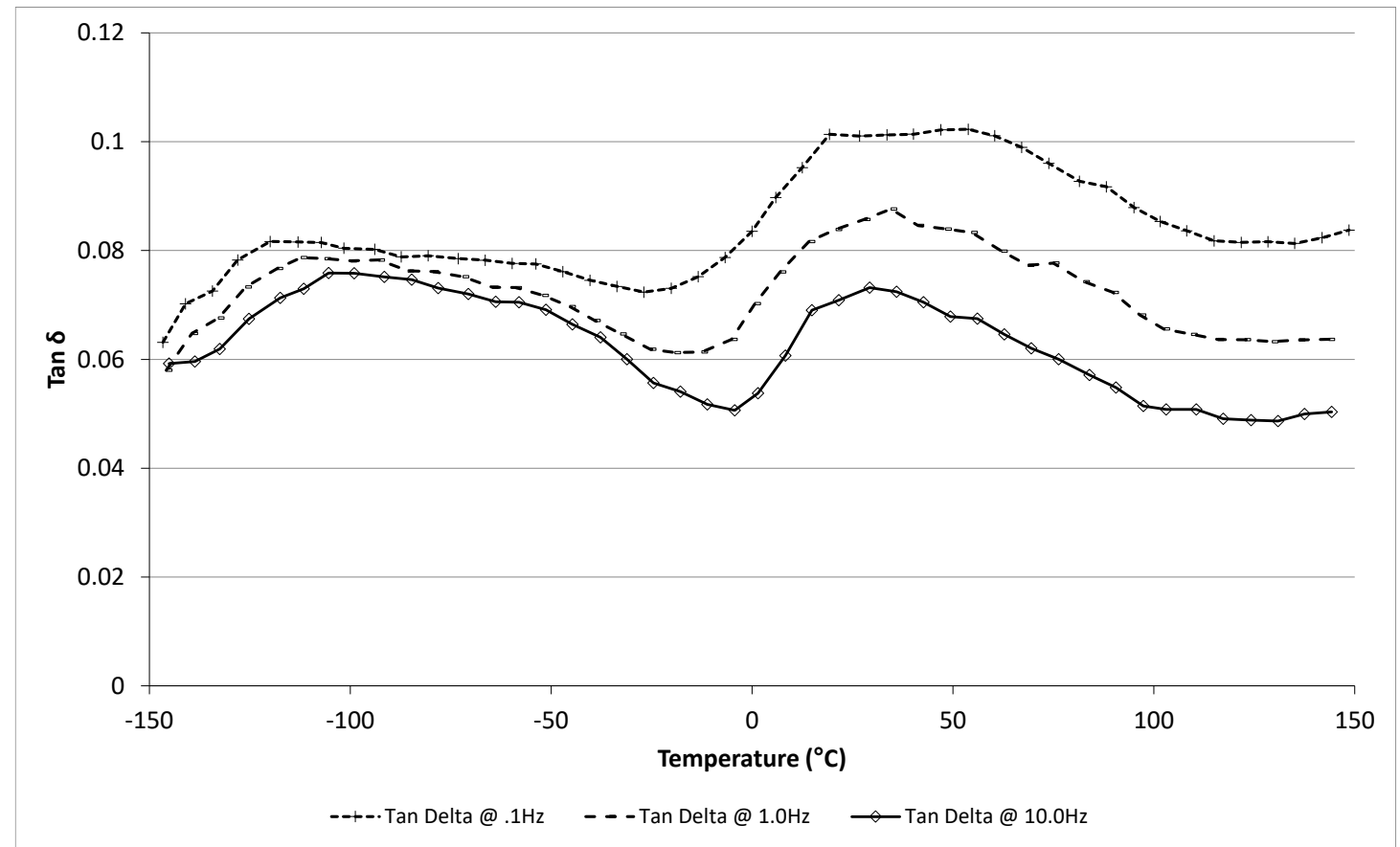


c)

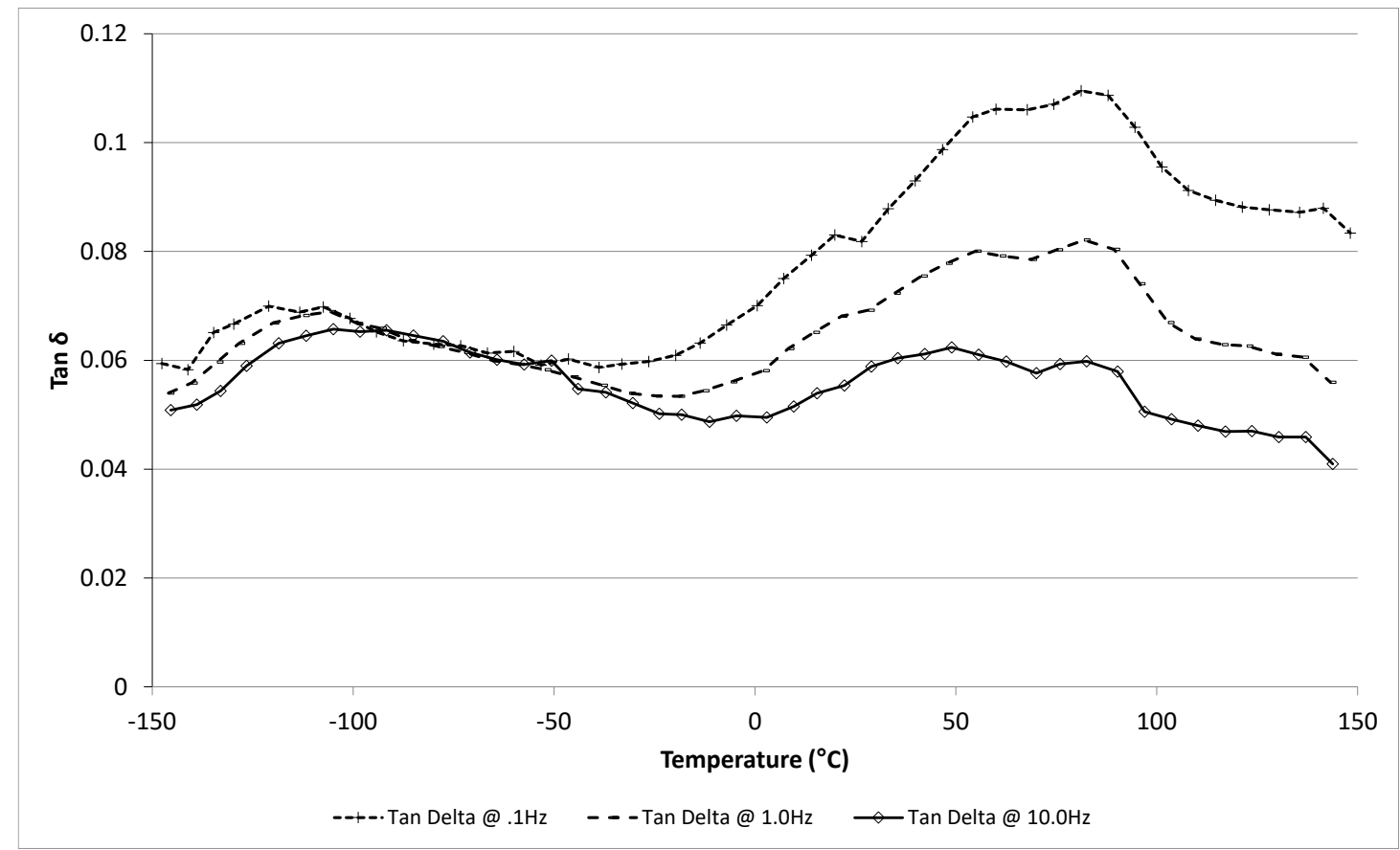

d)

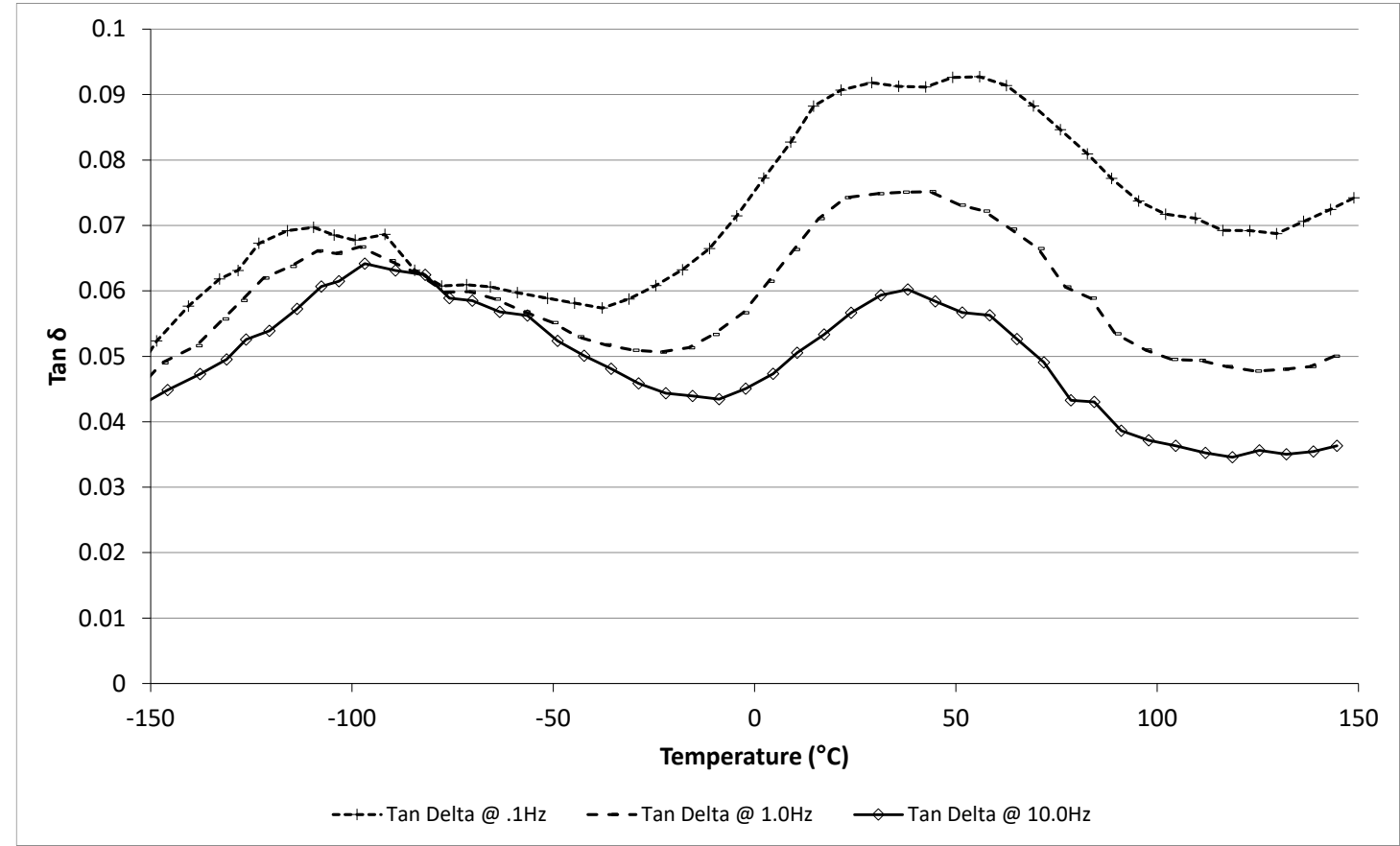

Figure 2. Loss factor ( $\tan \delta$ ) for (a) Scots pine, (b) Obeche, (c) Gmelina and (d) Alstonia wood. 
a)

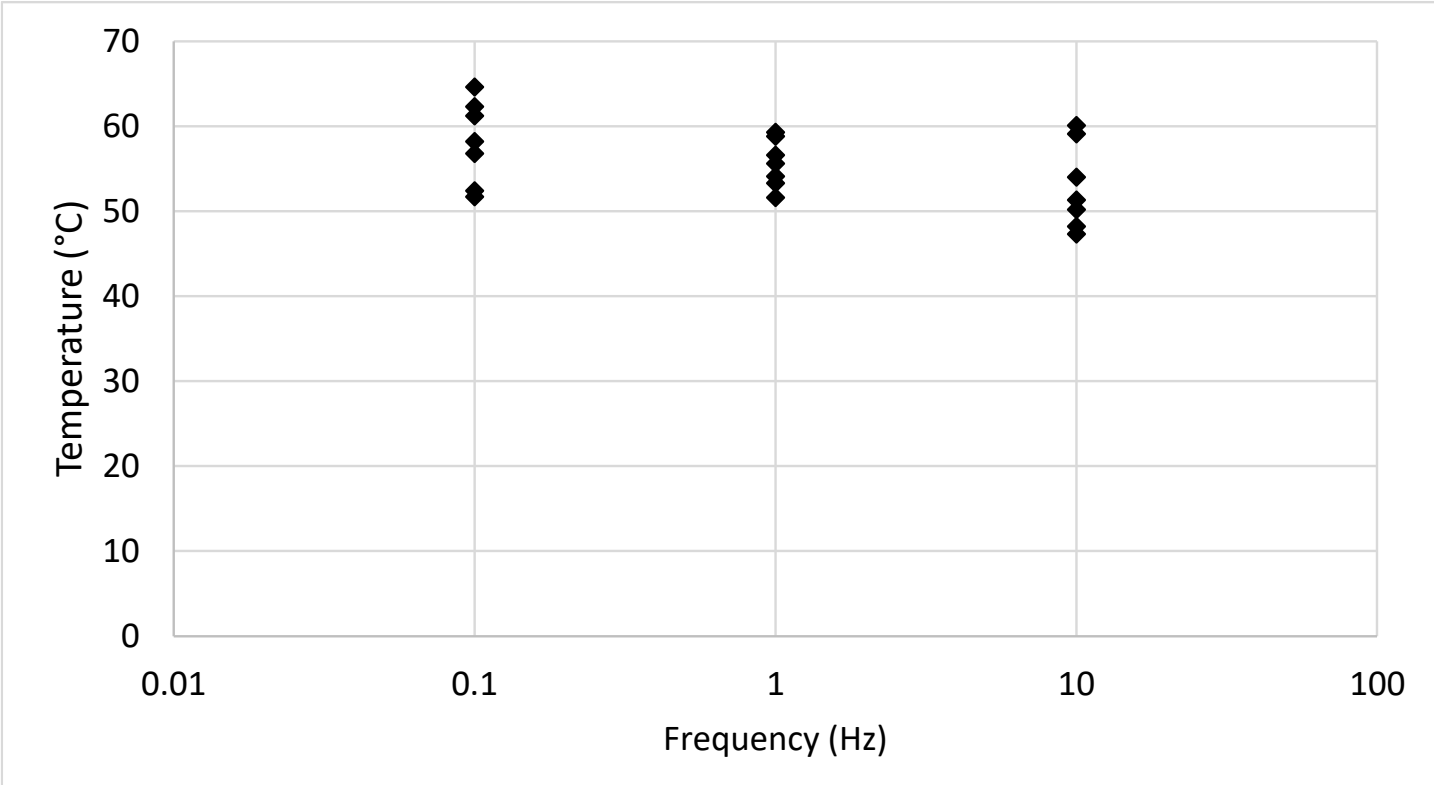

b)

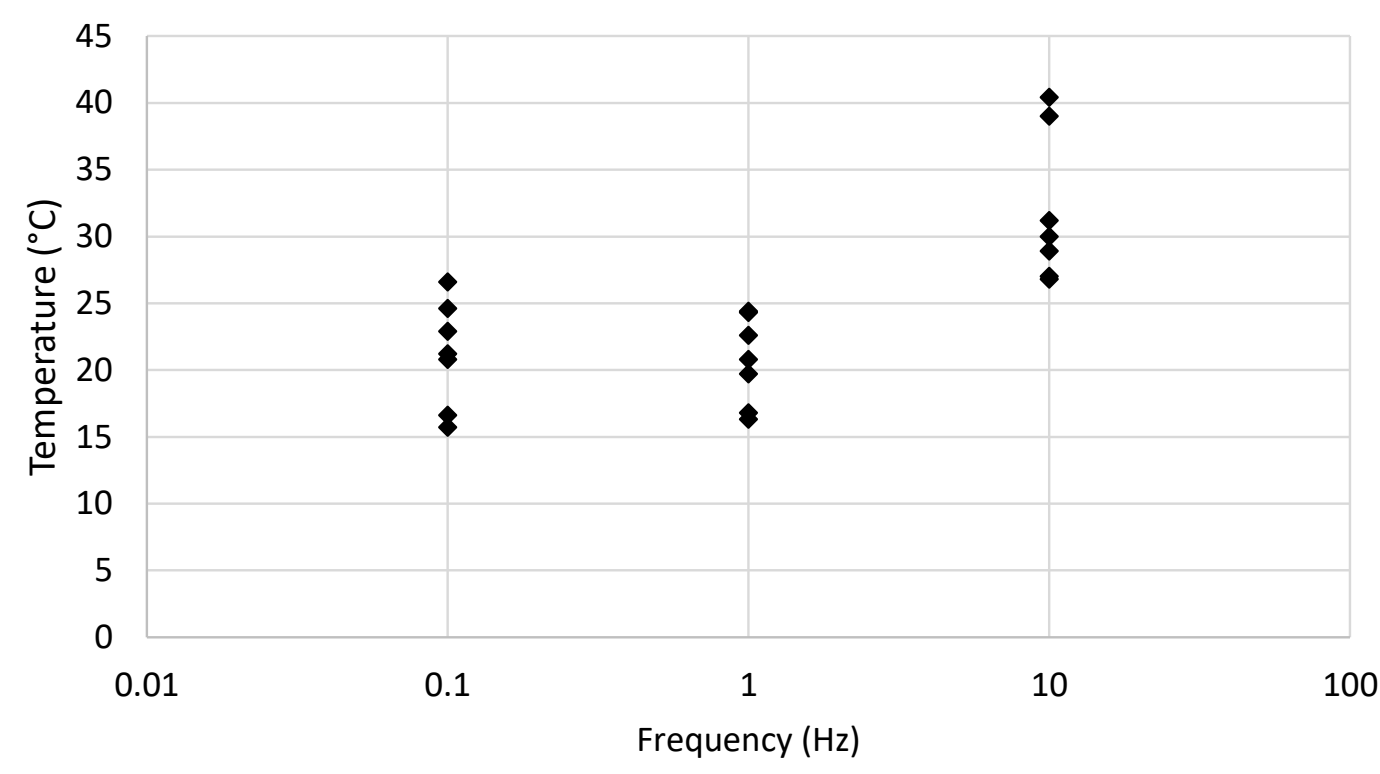


c)

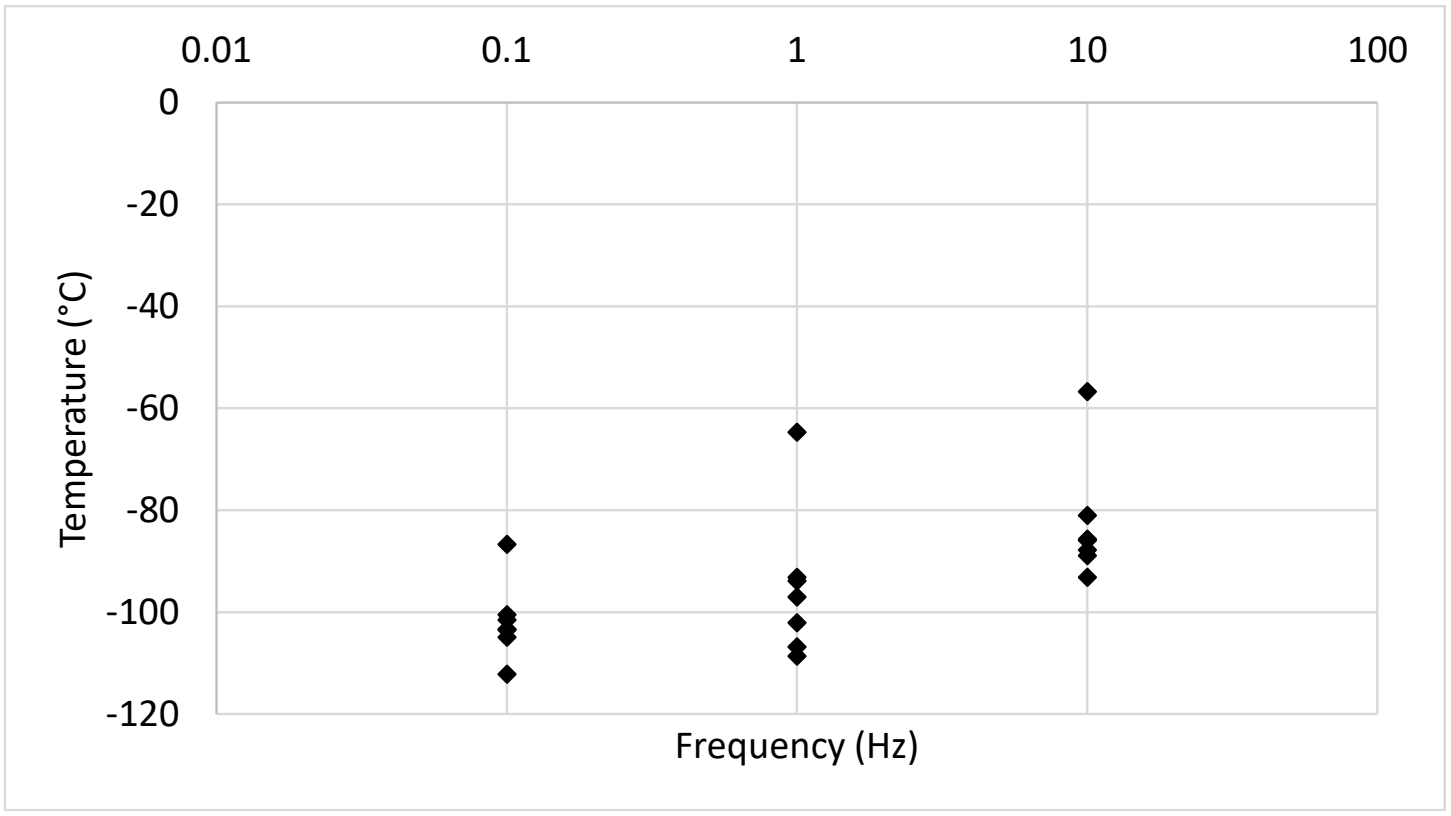

Figure 3. Temperature of the occurrence of $\tan \delta$ events in DMA scans on Scots pine (a) beta 1 relaxation, (b) beta 2 relaxation, (c) gamma relaxation. 
Dynamic mechanical analysis of Scots pine and three tropical hardwoods

Tables

\begin{tabular}{|c|c|c|c|}
\hline Peak & $\begin{array}{l}\text { Attribution made by } \\
\text { Sugiyama et al. (1998) }\end{array}$ & Temperature & $\begin{array}{l}\text { Observations by other } \\
\text { researchers }\end{array}$ \\
\hline$\alpha$ & $\begin{array}{l}\text { Micro-Brownian } \\
\text { motions of the cell wall } \\
\text { polymers in the non- } \\
\text { crystalline region, } \\
\text { dominated by lignin } \\
\text { component }\end{array}$ & above $150^{\circ} \mathrm{C}$ & $\begin{array}{l}\text { Occurring at } 70 \text { to } 120^{\circ} \mathrm{C} \text { for } \\
\text { saturated wood and } 150 \text { to } \\
230^{\circ} \mathrm{C} \text { for fully dry wood } \\
\text { (Havimo } 2009 \text {, Sharma et al. } \\
\text { 2015) } \\
\text { Glass transition above } 200^{\circ} \mathrm{C} \\
\text { in air dry wood (Startsev et al. } \\
\text { 2017) }\end{array}$ \\
\hline$\beta$ & $\begin{array}{l}\text { Rotational motion of } \\
\text { moisture within wood }\end{array}$ & $-40^{\circ} \mathrm{C}$ & $\begin{array}{l}\text {-33 down to }-98^{\circ} \mathrm{C} \text { depending } \\
\text { on moisture content (Obataya } \\
\text { et al. 2001); } \\
\text { occurring at higher } \\
\text { temperatures up to } 50^{\circ} \mathrm{C} \text { as } \\
\text { moisture content decreases } \\
\text { (Backman and Lindberg } 2001 \text {, } \\
\text { Havimo } 2009 \text {, Sharma et al. } \\
\text { 2015) }\end{array}$ \\
\hline$\gamma$ & $\begin{array}{l}\text { Motions of } \mathrm{CH}_{2} \mathrm{OH} \\
\text { groups of the cell wall } \\
\text { polymers in the non- } \\
\text { crystalline region }\end{array}$ & $-110^{\circ} \mathrm{C}$ & $\begin{array}{l}-80^{\circ} \mathrm{C} \text { (Havimo } 2009, \text { Sharma } \\
\text { et al. 2015) }\end{array}$ \\
\hline
\end{tabular}

Table 1: Summary of molecular motions and wood components related to the $\tan \delta$ loss factor peaks observed in wood. 


\begin{tabular}{|l|l|l|l|l|}
\hline & $\begin{array}{l}\text { Density } \\
\text { (oven dry) } \\
\mathrm{g} / \mathrm{cm}^{3}\end{array}$ & $\begin{array}{l}\text { MOE in } \\
\text { bending } \\
\text { GPa }\end{array}$ & MC at test & $\begin{array}{l}\text { Number of } \\
\text { replicates }\end{array}$ \\
\hline Scots pine & 0.41 & $10^{1}$ & $8-9 \%$ & 7 \\
\hline Obeche & 0.34 & $5.5^{1}$ & $8-9 \%$ & 3 \\
\hline Gmelina & 0.37 & $6.3^{1}$ & $8-9 \%$ & 3 \\
\hline Alstonia scholaris & & & $8-9 \%$ & 3 \\
\hline $\begin{array}{l}\text { Pulai } \\
\text { (Alstonia } \text { spp.) }\end{array}$ & $0.36^{2}-0.45^{3}$ & $4.1^{3}$ & & \\
\hline Alstonia boonei & & $8.3^{4}$ & & \\
\hline
\end{tabular}

Table 2: Properties of the timbers studied. Additional sources of information, if from literature, are indicated by superscript as follows: ${ }^{1}$ Lavers $1969,{ }^{2}$ Hadi et al. 2012 (this value for Pulai, Indonesia), ${ }^{3}$ Islam et al. 2012a (data for Pulai,), ${ }^{4}$ Lavers 1969 (this value for Alstonia boonei, Uganda,) 


\begin{tabular}{|c|c|ccc|}
\hline \multirow{2}{*}{ Species } & Loss factor & \multicolumn{3}{|c|}{ Tan $\boldsymbol{\delta}$ peak temperature $\left({ }^{\circ} \mathbf{C}\right)$} \\
\cline { 3 - 5 } & (Tan $\boldsymbol{\delta})$ & $\mathbf{0 . 1 ~ H z}$ & $\mathbf{1 ~ H z}$ & $\mathbf{1 0 ~ H z}$ \\
\hline peak & & 58.2 & 55.6 & 52.9 \\
& $\beta_{1}$ & 21.2 & 20.7 & 31.9 \\
& $\beta_{2}$ & -101.8 & -95.2 & -82.7 \\
\hline \multirow{4}{*}{ Pinus sylvestris } & $\gamma$ & 51.7 & 50.7 & 49.7 \\
& $\beta_{1}$ & 27.4 & 30.8 & 32.0 \\
& $\beta_{2}$ & 4.7 & 19.2 & 20.6 \\
& $\beta_{3}$ & -72.8 & -71.9 & -68.0 \\
& $\gamma_{1}$ & -108.6 & -102.0 & -92.2 \\
\hline \multirow{5}{*}{ Gmelina arborea } & $\gamma_{2}$ & 83.2 & 81.9 & 78.6 \\
& $\beta_{1}$ & 60.4 & 52.9 & 51.7 \\
& $\beta_{2}$ & 20.2 & 23.9 & 31.6 \\
& $\beta_{3}$ & -72.3 & -68.0 & -62.9 \\
& $\gamma_{1}$ & -108.2 & -106.4 & -99.9 \\
\hline \multirow{3}{*}{ Triplochiton } & $\gamma_{2}$ & 80.7 & 77.25 & 74.8 \\
scleroxylon & $\beta_{1}$ & 53.6 & 52.1 & 51.3 \\
& $\beta_{2}$ & 26.4 & 32.3 & 29.2 \\
& $\beta_{3}$ & -50.8 & -56.2 & -55.1 \\
& $\gamma_{1}$ & -114.6 & -107.3 & -98.1 \\
\hline
\end{tabular}

Table 3: Average values for the temperature $\left({ }^{\circ} \mathrm{C}\right)$ at which the loss factor $(\tan \delta)$ peak was observed in Scots pine, Alstonia, Gmelina and Obeche, tested at different frequencies $(\mathrm{Hz})$. 


\begin{tabular}{|l|ccc|}
\hline \multirow{2}{*}{ Wood Species } & \multicolumn{3}{c|}{$\boldsymbol{E}^{\prime}(\mathbf{G P a})$ at different frequency } \\
\cline { 2 - 4 } & $\mathbf{0 . 1} \mathbf{~ H z}$ & $\mathbf{1 ~ H z}$ & $\mathbf{1 0 ~} \mathbf{~ H z}$ \\
\hline Pinus sylvestris & 6.3 & 6.6 & 7.0 \\
\hline $\begin{array}{l}\text { Triplochiton } \\
\text { scleroxylon }\end{array}$ & & & \\
\hline Gmelina arborea & 4.0 & 4.2 & 4.2 \\
\hline Alstonia scholaris & 5.2 & 5.4 & 5.5 \\
\hline
\end{tabular}

Table 4: Mean storage modulus (E') of Scots pine, Obeche, Gmelina and Alstonia at room temperature $\left(20-25^{\circ} \mathrm{C}\right)$ using different frequencies. 